\title{
Two Fascinating Polysaccharides: Chitosan and Starch. Some Prominent Characterizations for Applying as Eco-Friendly Food Packaging and Pollutant Remover in Aqueous Medium. Progress in Recent Years: A Review
}

\author{
Nancy Alvarado ${ }^{1, *}$, Romina L. Abarca ${ }^{2}(\mathbb{D})$ and Cristian Linares-Flores ${ }^{3} \mathbb{D}$ \\ 1 Instituto de Ciencias Químicas Aplicadas, Facultad de Ingeniería, Universidad Autónoma de Chile, \\ El Llano Subercaseaux 2801, San Miguel 8900000, Chile \\ 2 Departamento de Ciencias Animales, Facultad de Agronomía e Ingeniería Forestal, Pontificia Universidad \\ Católica de Chile, Macul, Santiago 7820436, Chile; romina.abarca@uc.cl \\ 3 Grupo de Investigación en Energía y Procesos Sustentables, Instituto de Ciencias Químicas Aplicadas, \\ Facultad de Ingeniería, Universidad Autónoma de Chile, El Llano Subercaseaux 2801, \\ San Miguel 8900000, Chile; cristian.linares@uautonoma.cl \\ * Correspondence: nancy.alvarado@uautonoma.cl; Tel.: +56-98775457
}

check for updates

Citation: Alvarado, N.; Abarca, R.L.; Linares-Flores, C. Two Fascinating Polysaccharides: Chitosan and Starch. Some Prominent Characterizations for Applying as Eco-Friendly Food Packaging and Pollutant Remover in Aqueous Medium. Progress in Recent Years: A Review. Polymers 2021, 13 1737. https://doi.org/10.3390/ polym13111737

Academic Editor: Florian J. Stadler

Received: 3 May 2021

Accepted: 19 May 2021

Published: 26 May 2021

Publisher's Note: MDPI stays neutral with regard to jurisdictional claims in published maps and institutional affiliations.

Copyright: (C) 2021 by the authors. Licensee MDPI, Basel, Switzerland This article is an open access article distributed under the terms and conditions of the Creative Commons Attribution (CC BY) license (https:// creativecommons.org/licenses/by/ $4.0 /)$.
Abstract: The call to use biodegradable, eco-friendly materials is urgent. The use of biopolymers as a replacement for the classic petroleum-based materials is increasing. Chitosan and starch have been widely studied with this purpose: to be part of this replacement. The importance of proper physical characterization of these biopolymers is essential for the intended application. This review focuses on characterizations of chitosan and starch, approximately from 2017 to date, in one of their most-used applications: food packaging for chitosan and as an adsorbent agent of pollutants in aqueous medium for starch.

Keywords: biopolymers; eco-friendly; food packaging; bio-adsorbent; physical characterization; waste

\section{Introduction}

The use of petroleum-based materials has been very effective and has improved our quality of life. However, the cost of our comfort is being paid by the environment due to the slow degradation of these materials, causing a huge accumulation of waste. It is urgent to change these materials of slow degradation and look for eco-friendly ones. In this research, chitosan (CS) and starch, two polysaccharides, have been extensively studied with the following purpose: to reduce the wastes from non-biodegradable materials $[1,2]$.

After cellulose, chitosan is the most abundant biopolymer on our planet. This polysaccharide comes from the deacetylation of chitin, which is mainly present in the shell of crustaceans, insects, and marine invertebrates [1,3]. Worldwide, the production of cultured crustaceans reaches 11\%, which corresponds to 9.4 million tons (Figure 1) [4]. In this sense, this industry originates large amounts of wastes containing chitin, therefore, representing an important source of CS from waste that could be used. Meanwhile, starch is a biopolymer that can be obtained from plants and plant wastes such as tuber wastes. The worldwide production of products containing starch is huge, generating around 2000 million tons (Figure 2) [5]; thus, the wastes produced when obtaining starch can be a formidable source of this biopolymer. Its cheap and abundant qualities make it an attractive material to both academia and industry. 


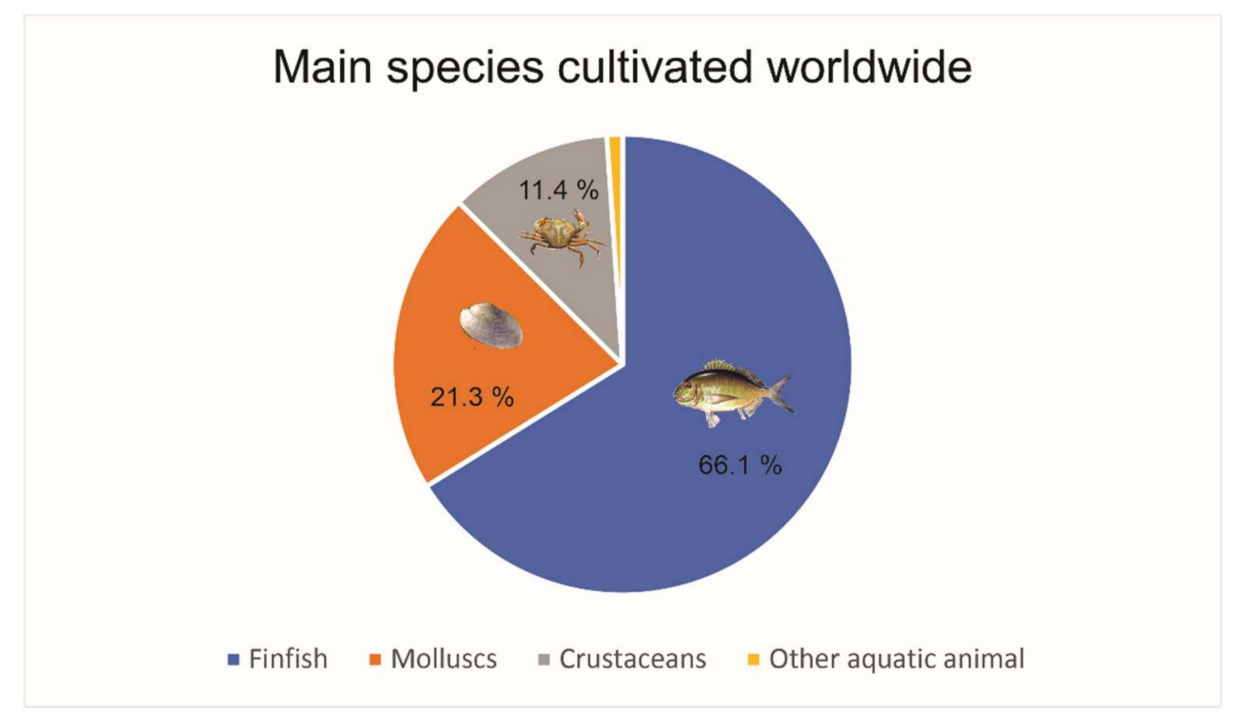

Figure 1. Main species cultivated worldwide in 2018 [4].

\section{Production of starch-containing foods}

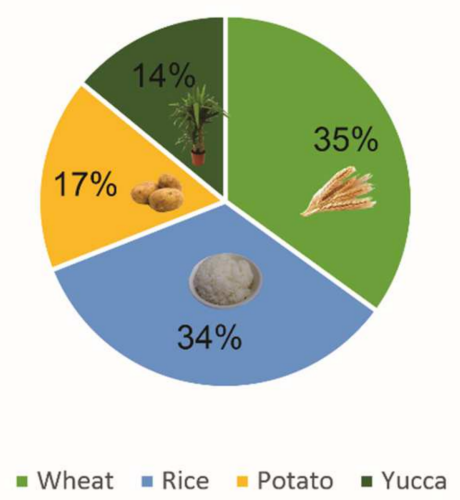

Figure 2. Starch-containing food products produced in 2019 [5].

Regarding the chemical structure of chitosan and starch, due to their nature as polysaccharides, both present $-\mathrm{OH}$ groups, and $\mathrm{CS}$ has $-\mathrm{NH}_{2}$ groups. The presence of these chemical groups is good since they allow chemical modifications. This characteristic gives versatility to these biopolymers as it could improve several physical characteristics and thereby extend the range of applications of these biopolymers. For instance, CS-modified through the introduction of imine and pyridine groups-was used as bioadsorbent of $\mathrm{Cr}(\mathrm{IV})$ and $\mathrm{Cu}$ (II) [6]. Meanwhile, when starch is treated with kaolin at high temperature, a starch with improved biodegradability properties is obtained [2]. Some of their applications are encapsulating agent [7-9], bio-adsorbent [10-18], foams [19-24], food packaging [25-33], and medical applications [34-42] (Figure 3).

Currently, it is well known that chemical modifications provide different, new, and improved materials. The blending between polymers, biopolymers, or composites is a cheap alternative that allows obtaining the desired material through the interactions. In this way, chitosan and starch have also been involved in several studies using this technique. These studies include the combination of biopolymers [43-52] and/or the incorporation of fillers, such as nanoparticles, fibers, and layers [47-71].

The antimicrobial capacity of CS, along with being biocompatible and non-toxic, provides unique features to this biopolymer which has been studied in depth with the 
goal of being applied in various fields such as pharmaceutical [72], medicine [41], food industry [73], etc. This review approaches some characterizations that describe and support classic methods concerning the use of chitosan in the food packaging industry and starch as pollutants remover. With this, it is expected to achieve a better understanding of the physical properties of these biopolymers in these specific fields.

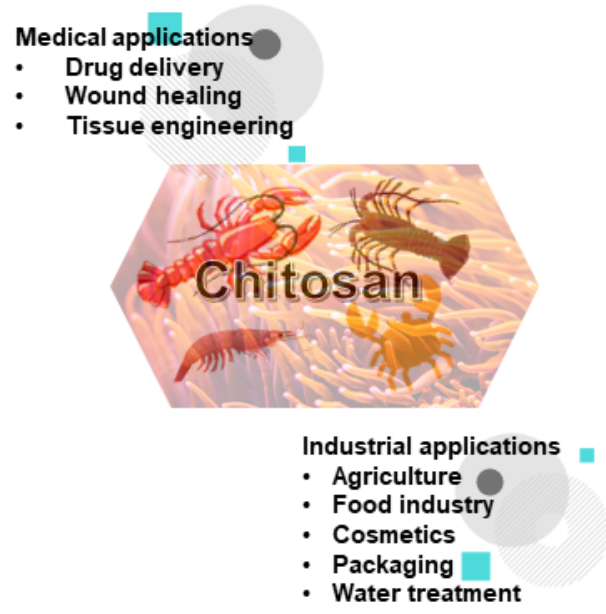

Figure 3. Some chitosan applications.

\section{Chitosan (CS)}

The focus on biopolymers such as CS has increased due to the shortage of the fossil fuel reserve and the environmental impact induced by the accumulation of non-biodegradable plastic-based traditional packaging materials. This serious problem affects not only marine life but also humans, as microplastics can enter the food chain and eventually harm health [74]. It has been predicted that the global turnover of bioplastic manufacturing will increase 2.6 times from 2017 to 2022, reaching US \$43.87 [75]. Currently, different biopolymers are obtained from food waste, which contributes to reducing "waste and at the same time diversifying food packaging materials. Thereby, CS is an alternative to synthetic polymers and a raw material for new materials" [76]. It is a natural material that has undergone widespread research in recent years. Most biopolymers, such as CS, are inherently weak regarding their physical, mechanical, and thermal attributes when compared to widely used petro-based polymers (i.e., polyethylene, polyvinyl alcohol, polystyrene) [77]. In the specific case of chitosan-based compounds, they become relevant because of their applications in food packaging and because they can be used in different ways [78-80].

The use of biopolymers on a large scale is still limited, "due to its high cost and lower performance based on poor barrier against water vapor; lower thermal, optical and mechanical properties when compared to traditional petroleum-based plastics" [81]. The versatile structural and magnificent characteristic of CS, as well as chemical modifications and nanobiotechnology creativity, permit the development of a series of chitosan-based nanomaterials and composites with interesting properties [82]. Below are a series of analyses used to characterize chitosan-based films, including their mechanical, physical, and thermal properties, among others.

\subsection{Mechanical Properties of CS}

Investigating the mechanical properties in food packaging is very important since, by knowing them, their adequate application is possible. The requirements concerning the mechanical properties of packaging are good tensile strength, flexibility, necessary elongation, and resistance to drilling, to generate a physical barrier and providing a longer shelf life to the food [83]. To verify that a material possesses good characteristics for use in food packaging, one or more of the reference parameters listed below can be used: 
maximum stress (tensile strength, TS) (MPa), Young's modulus of elasticity (EM) (MPa) from the stress-strain curves, and film extensibility (elongation at break, \%EAB) from the force-distance curves are determined using Equations (1)-(3), respectively.

$$
\begin{gathered}
\operatorname{TS}(M P a)=F_{\text {max }} / A_{0} \\
\operatorname{EAB}(\%)=\left[\Delta l / l_{0}\right] \times 100 \\
E M=L_{0}\left(F_{2}-F_{1}\right) / A_{0}\left(\delta_{2}-\delta_{1}\right)
\end{gathered}
$$

where $F_{\text {max }}$ is the maximum load for breaking the film $(\mathrm{N})$, Ao is the initial specimen

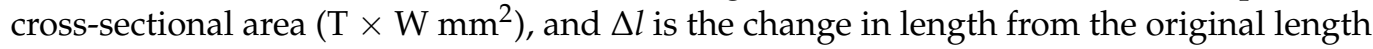
$\left(l_{0}\right)$ of the specimen between the grips. The force $\left(F_{1}, F_{2}\right)$ and displacement $\left(\delta_{1}, \delta_{2}\right)$ values were obtained using the linear portion of a plot of displacement against force [84].

CS film with various concentrations of green-synthesized silver nanoparticles (AgNP) (100-400 $\mu \mathrm{g}$ ) incorporated was developed by Mohamed and Madian [85] to obtain improved mechanical and antimicrobial properties. The authors indicate that the mechanical properties of the CS film with $\operatorname{AgNp}(300,400 \mu \mathrm{g})$ showed improved mechanical properties over the CS film, so the incorporation of a specific agent could improve the mechanical properties of the neat CS. Traction tests-developed by Almeida et al. [86]—were carried out for the mechanical characterization of the films tensile strength, elongation at break, elastic modulus of films-based CS, sodium acetate (NaA), and galactomannan (Gal). The values of the TS, EAB, and EM indicated that the films with Gal show lower values of $E A B$ regarding $C S$ and $C S-N a A$ films, meanwhile with the addition of $\mathrm{NaA}$ had a lower $E A B$ value (CS-Gal-NaA: $67.11 \pm 0.89 \%$ ), showing the statistical difference from the other films with $p<0.05$. They observed that the most resistant packaging is the least flexible, showing lower $E A B$ values. CS films exhibited the highest values of $E A B$ and the lowest TS values. When NaA compound was incorporated a decrease in the value of TS of CS films $(p>0.05)$ was observed. The above "suggests that the incorporation of NaA compounds in the CS films generate to a decline in the intermolecular interactions" of the films. In this way, the crystallinity of the polymeric material is a parameter that must be taken into account since, an increase in the crystallinity of films can be associated with elastic with higher values of $E A B$ and more breakable with lower values of TS films. Thus, the EM is a signal of the stiffness of the material, therefore, the larger the modulus, the more rigid the material.

Another analysis of mechanical properties carried out under the standard ASTM (American Society for Testing and Materials) D882 method through a testing machine shows that concerning the stress-strain curve of chitosan-based films with added gelatin (ge) and Quercetin/starch (Q). In this study, the mechanical properties of CS-based films were notoriously changed. TS value of the pure chitosan film was $10.54 \pm 0.0565 \mathrm{MPa}$. With the addition of ge and Q, TS increased to $16.10 \pm 0.1414$ and $17.11 \pm 0.3464 \mathrm{MPa}$, respectively. They found that higher TS in chitosan-based films could be due to better affinity of mixed CS and ge/Q. The increase observe of TS could also be related with the increased structural interaction between CS and Q. Besides, after the incorporation of ge/Q into the CS film, the $E A B$ of the chitosan films reduced notoriously. The $E A B$ of pure CS film was $11.04 \pm 0.0565 \%$, which decreased to $9.34 \pm 0.4242$ for CS-ge film and $5.100 \pm 0.3162 \%$ for CS-ge-Q film. This could be due to the increased stiffness of CS-based films, considering that the formation of microspores and holes in the films because of the incorporation of $Q$ which is observed from the superficial analysis [87]. The results of the incorporation of active agents, such as essential oils (e.g., eugenol (EU)), into the CS film on the mechanical properties have been studied by Zheng et al. [88]. They investigated TS and EAB for CS, CS-Acorn Starch (AS), and CS-AS-EU films. When CS-AS films were measured, they found that the TS values were higher regarding CS film. This increase in TS values of the film would be related to the intermolecular forces generated like hydrogen bonds between the $\mathrm{NH}_{3}{ }^{+}$of $\mathrm{CS}$ and the $\mathrm{OH}^{-}$of AS, thus enhancing the density of the final material. The $E A B$ parameter value of the films were markedly changed due to incorporation of the AS. On the 
other hand, the $E A B$ value partially decreased (68.5\% to $60.4 \%$ ) as the mass ratio of AS to CS increased by 0.9 , showing a marked decrease in $E A B$ and a further increase in AS contents.

Despite, the fact that different initiatives propose to develop biodegradable plastics, the mechanical and/or transport properties of these materials are parameters that still need to be improved to replace conventional plastic packaging materials and dispense with them entirely [89].

\subsection{Barrier Property}

In general, the barrier properties are defined as a module used to study the performance of films and/or packaging in food preservation. Among the barrier properties are oxygen barrier, water vapor, and light barrier property, the first two being the most relevant. The above are closely related to processes such as oxidation, microbial growth and food spoilage [90].

\subsubsection{Water Vapor Permeability (WVP)}

The prevention of transfer moisture between food and the surrounding atmosphere is one of the main goals of food packaging materials. In this sense, the water vapor permeability (WVP) value must be very low [91]. Water vapor from the surrounding atmosphere can transfer to packaged foods, threatening the shelf life of foods by affecting quality and causing spoilage. The transfer of water either from or to the packaged food can negatively affect food products, generating changes at the structural and/or sensory level of these. WVP quantifies the amount of water that diffuses through the film per unit area and time $(\mathrm{g} / \mathrm{s} \mathrm{m} \mathrm{Pa})$, depending on the thickness and the differential pressure of the film [92]. WVP is calculated according to the combined Fick and Henry laws for gas diffusion through films, using Equation (4):

$$
W V P=\frac{\Delta w \cdot x}{\Delta t \cdot A \cdot \Delta P}
$$

where $\Delta w / \Delta t(\mathrm{~g} / \mathrm{s})$ is the flux measured as weight loss of the cell per unit of time, $x(\mathrm{~m})$ is the film thickness, $A\left(\mathrm{~m}^{2}\right)$ is the exposed area, and $\Delta P(P a)$ is the water vapor-pressure deficit. WVP values are obtained gravimetrically following the ASTM Standard Test Method E96 [93].

Lyn et al. [94] elaborated CS films with the incorporation of graphene oxide (GO). They observed that for neat CS films, WVP decreased slightly $(p \geq 0.05)$ with the increasing heating temperature. This could be due to thermal crosslinking within the CS matrix, which increases tortuosity in the CS matrix. In the films with GO incorporated to CS matrix (CSGO) WVP decreased $(p<0.05)$. The researchers observed that temperature is a factor to consider, since they subjected the CSGO films to a thermal sweep between 60 and $120^{\circ} \mathrm{C}$ and that the values obtained from WVP were significantly lower $(p<0.05)$ than when the films they were heated to $30^{\circ} \mathrm{C}$. The authors indicate that the findings of other authors have found similar results and attribute the decrease in WVP to a denser film matrix due to intense structural collapse when the film was heated to a high temperature.

In another work, Lin et al. [92] showed that the moisture permeability of composite films based on chitosan/okra powder/nano-silicon airgel compound increased slightly with increasing content of CS and nano-silicon airgel, but with a low difference. Based on its chemical structure, CS showed a better interaction with water molecules and aids in the transport of water vapor molecules through the film. At the same time, they observed a better desorption and adsorption of $\mathrm{H}_{2} \mathrm{O}$ molecules due to the incorporation of glycerol, which acts as a plasticizer. Consequently, due to the increase in CS, the hydrophilicity of the final material increased, which caused the dissolution of a significant part of the water vapor in the film and, therefore, the increase of the $W V P$ value. 


\subsubsection{Oxygen Transmission Water (OTR)}

Oxygen causes a change in the quality of food if it enters the inner package. Oxygen permeability or oxygen transmission rate can measure the oxygen barrier characteristics of films: where the permeability or transmission higher, the poorer oxygen barrier property. Low oxygen transmission water (OTR) values indicates quite good oxygen barrier properties. Regarding CS-based films, it has been found that these have similar oxygen permeability values to the commercially available food packaging ethylene-vinyl alcohol copolymer films or polyvinylidene chloride films [90]. Oxygen permeability (OP) of films is determined using an automated oxygen permeability testing machine following the standard method (ASTM D3985-05, 2005). One side of the film sample is oxygen, and the other side is nitrogen. OTR and OP are calculated according to Equation (5):

$$
O P=O T R \times \frac{d}{\Delta P^{*}}
$$

where $d$ is film thickness (mm), and $\Delta P^{*}$ is the partial pressure of oxygen [95].

Narasagoudr et al. [96] developed active packaging films based on CS, poly(vinyl alcohol) (PVA), and boswellic acid (BA). They evaluated the effect of BA compound on several properties of CS/PVA (CPBA) based active films. In this study, the OTR values of the CS film was 1197, film poly(vinyl alcohol) (PVA) 480, and CS/PVA film was $691 \mathrm{cc} /\left(\mathrm{m}^{2} \cdot \mathrm{d} \cdot \mathrm{atm}\right)$. The OTR of the CPBA films ranged from 219.70 to $245.53 \mathrm{cc} /\left(\mathrm{m}^{2} \cdot \mathrm{d} \cdot \mathrm{atm}\right)$. They observed that the incorporation of BA into the CS/PVA matrix significantly decreased the OTR values of the CPBA active films. The described fact could be attributed to the hydrogen bonds present in the final material. This study demonstrates that in the case of CS-based films, the barrier properties can be improved with the incorporation of various components chemically compatible with the CS polymer matrix.

\subsection{Optical Properties}

Among the optical properties, color and opacity are considered. Both are important parameters in the appearance of packaged foods since they affect the degree of acceptance by the consumer [97]. In the case of color, the luminosity values $\left(\mathrm{L}^{*}\right)$ and chromatic coordinates $\left(a^{*}\right.$ and $\left.b^{*}\right)$ of the film are evaluated by reflectance measurements. Here, $\mathrm{L}^{*}$ ranging from black to white, and the horizontal axes, indicated by $\mathrm{a}^{*}$ and $\mathrm{b}^{*}$, ranging from $-a^{*}$ : greenness, $-b^{*}$ : blueness, to $+a^{*}$ : redness, $+b^{*}$ : yellowness. The values of $a^{*}$ and $\mathrm{b}^{*}$ approach zero for neutral colors and increase as the color becomes more chromatic and more saturated [86].

Color difference $\left(\Delta E^{*}\right)$ is calculated by Equation (6):

$$
\Delta E^{*}=\sqrt{\left(\Delta L^{*}\right)^{2}+\left(\Delta a^{*}\right)^{2}+\left(\Delta b^{*}\right)^{2}}
$$

where: $\Delta \mathrm{L}^{*}=\mathrm{Lstandard} *-\mathrm{Lfilm} * ; \Delta \mathrm{a}=$ astandard $*-\operatorname{afilm} *$; and $\Delta \mathrm{b} *=$ bstandard $*-$ bfilm* [97].

In a study, a CS film based was developed, where zinc oxide $(\mathrm{ZnO})$ particles $(0,1$, and $3 \%(W / V)$ ) and Melissa essential oil (MEO) $(0,0.25$, and $0.5 \%(W / V))$ were used with the aim of improving the biopolymer properties. The film color study using a colorimeter showed that pure CS film has a clear, yellowish appearance. Meanwhile, the composite films exhibited a great difference when compared with the pure CS films. With the increase of the concentrations of Melissa essential oils and zinc oxide they observed that the brightness parameter $L^{*}$ decreased. The researchers concluded that this result is due to the phenolic compounds present in the films which have the spectroscopic characteristic that can absorb light at low wavelengths. In a study that used the same $E O$ in a mucilage film, similar results were obtained. They observed that with increasing concentrations of MEO and zinc oxide nanoparticles, the value of $\mathrm{a}^{*}$ increases, and the color of the samples tends to be red. The color of the films tends to yellow when the concentration of MEO increases. 
On the other hand, the films with high concentrations of zinc oxide results clouded. This result can be due to the agglomeration of zinc oxide Np in the CS films [98].

Reflectance measurements are used to describe the opacity of a material. Besides, opacity allows measuring light transmittance of the films, through an ultraviolet-visible (UV-Vis) spectrometer in the wavelength range of $200-800 \mathrm{~nm}$. Film opacity is determined by measuring absorbance at $600 \mathrm{~nm}$ and calculated by the Equation (7):

$$
\text { Opacity }=\frac{\mathrm{A}_{600}}{\mathrm{t}}
$$

where $A_{600}$ is the absorbance at $600 \mathrm{~nm}$ wavelength and $t$ is the thickness of the film (mm) [99].

Xu et al. [100] developed CS-gum arabic-based polyelectrolyte films complexed with cinnamon essential oil (CEO) and clove essential oil (CLO). They analysed the opacity, observing an increase from 0.71 to 2.53 when the CEO increased ( $0 \%$ to $15 \%$ ) in the polymer matrix. These results could be attributed to the increased intensity of light-scattering induced by the increasing size of CEO and CLO droplets within the film matrix, therefore, the changes in the opacity parameter are due to the increase in oil in the polymer matrix. Regarding films containing CLO, they resulted in the most transparent. While the addition of CEO increased the yellowish color of control films, which interfered in of Schiff-base reaction between CS and CEO. They concluded that this organic reaction between CS and CEO would help the chemical compatibility of the CS/CEO film. Base opacity of CS films can increase or decrease depending on the active agent that is incorporated into the matrix of the polymer and the greater or lesser affinity they have with it. Both color and opacity of food containers are relevant factors for the choice of consumers. In addition, the opacity parameter plays an important role in sensitive to light foods.

\subsection{Antimicrobial Activity}

CS is biopolymer that has outstanding antimicrobial activity against several microorganisms such as bacteria (Gram-negative and Gram-positive), filamentous fungi, and yeast [101,102]. Many studies have investigated and demonstrated the antimicrobial properties of CS, however, the mechanism of action is still diffuse [103]. In contrast, the antibacterial activity is a complex process that most of presents differences in effectiveness between Gram positive and Gram-negative bacteria due to the different characteristics of the cell surface [104]. Rapa et al. [105] studied the effect of the biopolymer CS concentration on the properties of films containing poly (lactic acid) (PLA) plasticized with tributyl $O$-acetyl citrate (ATBC). The samples were arranged as films and sheets (PLA/CS and PLA/ATBC and samples of neat PLA) to evaluate the changes in their properties and in the antimicrobial activity of these, especially with respect to the antifungal and antibacterial activity. The antifungal capacity was evaluated in Petri dishes with potato dextrose agar (PDA), directly exposing the samples and evaluating inhibition halos and in the case of antibacterial analyzes, they were carried out based on the ISO 22196 standard.

In the case of the antifungal analysis, they evaluated the inhibition of the growth of different fungi such as Aspergillus brasiliensis, Fusarium graminearum and Penicillium corylophilum against the samples. The results regarding the inhibition rate (\% IR) at the contact surface were expressed as a percentage. \% IR against the fungus Aspergillus brasiliensis varied between $99 \%$ and $100 \%$ in the contact surface for both samples composed of PLA/CS, in the form of films and sheets, and they were compared with samples without CS. In all the cases analyzed, the \% IR values were higher for the sheets than for the film samples. They observed that with the increase in the amount of CS in the films, the \% IR values increased from $99.91 \%$ to $100 \%$.

On the other hand, \% IR against the fungus Fusarium graminearum were between $84.16 \%$ and $100 \%$ at the contact surface. By increasing the amount of CS in the mixture they observed that the value of \% IR 84.16 increased to $99.41 \%$ and finally, for Penicillium corylophilum they obtained IR between $94.5 \%$ and $100 \%$. Based on the results obtained 
it is possible to specify that both the amount of CS present in the mixture, as well as the form (film or sheet) influences the \% IR against the microorganisms tested. In the case of antibacterial analysis, they analyzed the effect of PLA samples with chitosan on Staphylococcus aureus and Escherichia coli. Samples (films and sheets) containing $1 \%$ or $3 \%$ CS showed a potent antibacterial effect, thus reducing approximately 2.7-2.8 log units compared to control or untreated PLA. In this case, the effects were diminished to values of $1 \log$ unit when increasing the CS to 5\%. The antimicrobial effect observed for E. coli was greater than for S. aureus. All samples containing CS showed excellent antimicrobial effect [106-109]. This study shows, on the one hand, that CS would be effective against more than one type of microorganism, filamentous fungi, as well as bacteria, but in the case of bacteria a greater activity against Gram-negative.

\subsection{Heat Resistence}

Commonly, thermal properties of polymers are studied through differential scanning calorimetry (DSC) and thermogravimetric analysis (TGA) [110]. In food packaging it is very important to quantify these properties with the aim of knowing the thermal stability of the materials that will be part of the food packaging system [111]. For thermal analysis, integrated DSC and TGA equipment or independent equipment can be used. Aguirre-Loredo et al. [112] studied glass transition temperature (Tg), related to the plasticization in biopolymers, such as CS. Tg indicates the temperature region at which a polymer changes from a solid state to a viscous state. In food packaging, changes in Tg is a pretty important parameter that can affect the quality of the product. They found that the glass transition temperature can change depending upon the composition and moisture content of the material.

Meng et al. [113] analyzed the thermal properties of starch-chitosan based films through DSC. First, a starch/chitosan film was observed showing the classic endothermic peak $\left(95.81^{\circ} \mathrm{C}\right)$ due to loss of water. Then, in the case of starch/chitosan films with peanut shell (in three different concentrations), for each of them they reported an endothermic peak with a higher temperature area, whose values fluctuate between $108.33^{\circ} \mathrm{C}, 140.90^{\circ} \mathrm{C}$ and $150.93^{\circ} \mathrm{C}$, respectively, as the concentration of the peanut shell in the starch/chitosan matrix increased. This result indicates that films with incorporated peanut shell extract are more thermally stable. However, different results were obtained when peanut skin extracts were incorporated into starch/chitosan films. As the concentration of this extract increased the endothermic peak decreased. The investigators indicated that this behavior can be explained through hydrogen bonding which is destroyed in the film matrix due to the high content of peanut skin.

Kizilkonka et al. [58] developed chitosan-based composite films with the incorporation of cerium oxide nanoparticles (NPs). They studied the thermal behavior of the films through TGA measures finding two main weight loss regions of the films. Thermal decomposition was observed between 180.24 and $460.97^{\circ} \mathrm{C}$, and this was attributed to dehydration of the saccharide rings, depolymerization, and decomposition of the acetylated and deacetylated units of the CS.

In a study by Koc et al. [114], they used a mushroom extract from Tricholoma terreum (edible mushrooms) to produce CS-based films. They studied a series of variables and parameters between those jointly studied by DSC (Figure 4A) and TGA (Figure 4B). In the DSC analysis, they observed the glass transition temperatures of both pure CS films and CS films with antifungal extract. In Figure $4 \mathrm{~A}$, it is possible to observe endothermic peaks for both films at 74 and $108^{\circ} \mathrm{C}$ respectively. These thermal events could be attributed to the loss of water from the films in the free state. Then other thermal events were observed linked to the glass transition temperature of CS at approximately $150{ }^{\circ} \mathrm{C}$, and in the case of the CS film with antifungal extract this value was increased $\left(195^{\circ} \mathrm{C}\right)$. These variations could be explained based on the increase in the number of hydroxyl groups forming intermolecular hydrogen bonds. At the same time, it was possible to observe a crystallization phenomenon of the films of pure CS and of CS with extract around 273 and $302{ }^{\circ} \mathrm{C}$, respectively. 

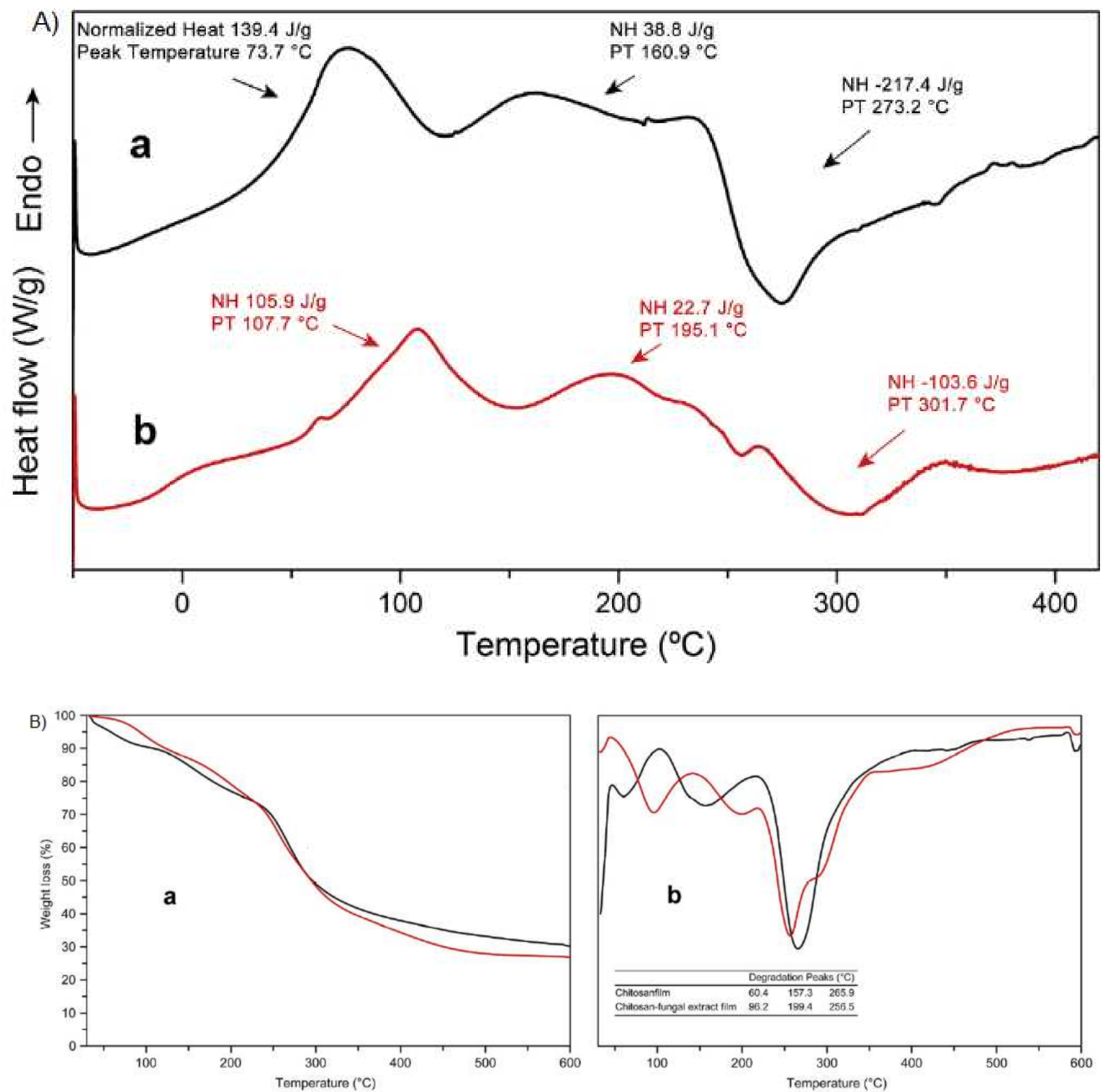

Figure 4. (A) Differential scanning calorimetry (DSC) thermograms of (a) chitosan and (b) chitosan with extract fungi incorporated in films; (B) (a) thermogravimetric analysis (TGA) and (b) DTGA (derivative thermogravimetric analysis) of chitosan and chitosan with extract fungi incorporated in films. (Reprinted from ref. [114]. Copyright 2020 with permission from Elsevier).

In the case of TGA (Figure 4B) for the same samples mentioned above, three mass drops were observed for the pure CS film and four in the case of the film with extract. In both cases the first degradation was associated with unbound water $\left(30-100^{\circ} \mathrm{C}\right)$, the second drop in mass was associated with the degradation of the plasticizer used $157^{\circ} \mathrm{C}$ and $199^{\circ} \mathrm{C}$ respectively, a third degradation was associated with the decomposition of CS $\left(266^{\circ} \mathrm{C}\right.$ and $\left.257^{\circ} \mathrm{C}\right)$, a value that varies according to the source of CS and other factors additional to its processing. A fourth mass loss was observed only in those films that contained the extract (above $270{ }^{\circ} \mathrm{C}$ ).

DSC and TGA were used to study the effect of agents on the stability of composites. The thermal degradation of the films was changed to higher temperatures with the incorporation of components, this indicates that adding components (such as nanoparticles, essential oils, other polymers, etc.) into the film matrix generates a thermal stabilization of the final material [114,115]. 


\subsection{Biodegradation}

Eco-friendly materials have become preferred alternatives both by the industry and consumers as part of food packaging, reducing the use of materials derived from fossil fuels. This is because it seeks to reduce the environmental impact of the tons of waste that are generated in the world [116]. The biodegradation process can be in accordance with ASTMD5338-15 [117]. Deshmukh et al. [99] prepared and characterized films based on CS, plasticizer (glycerol), and defatted Chlorella biomass (DCB) in terms of biodegradability.

They observed that the films initial structural integrity was missing. The films showed holes and loss of shape. The above indicates that the films react with the soil. The authors confirmed the structural and morphological changes by scanning electron microscopy (SEM) analysis. Surface degradation of pure chitosan film and CS $/ 25 \%$ DCB film was found before ( 0 days) and after 60 days of the test of being in contact with the soil. This indicates that there was a degradation of the films caused by microbes in the soil. The total weight loss of the samples is measured after the incubation period using Equation (8):

$$
\text { Weight Loss }(\%)=\frac{W_{1-} W_{0}}{W_{0}} \times 100
$$

where $W_{1}$ is the final weight of the specimens after incubation and $W_{0}$ is the initial weight of the specimens before incubation [118].

Zhu et al. [119] investigated the characteristics of polyelectrolyte complex (PEC) of chitosan and sodium cellulose sulfate (NaCS), focusing on the biodegradeability of CS, $\mathrm{NaCS}$, and chitosan/NaCS PEC films with pepsin, trypsin, lipase, alpha-amylase, and cellulase. The authors mention that previous studies on the degradation of chitosan indicate that the lytic activity of CS and the kinetic parameters of enzymes from different sources (even those of origin) change. For example, Aspergillus oryzae lipase, exhibited relatively low chitosan lytic activity, but Aspergillus niger lipase showed chitosan lytic activity comparable to chitosanase. Therefore, the speed and effectiveness of the degradation process will depend on the environment where it is carried out. Gan et al. [120] developed the cross-linking of cellulose nanocrystals (CNC)/CS composite films with glutaraldehyde (GA) as the cross-linking agent. To evaluate the biodegradation process, they used solid state fermentation to determine the ability of fungal isolates (Ophiocordyceps heteropoda, Enterobacter kobei and E. roggenkampii) in the degradation of the films. The filamentous fungi were cultured on PDA agar for more than a week at $30^{\circ} \mathrm{C}$. When evaluating the weight losses of the uncross linked and crosslinked CS 2composite films, an approximately linear relationship with biodegradation time was observed. The greatest weight loss was presented by the uncross linked pure CS film, and it was approximately $72 \%$ after 15 days of being in the soil.

The study shows that the degradation rate decreases in the composite films that containing CNC. Other authors also studied the biodegradation of CS samples but in compost. After 7 days of incubation, the CS films show remarkable physical changes such as swelling and were completely covered with the white mycelial growth of the compost microorganisms. Over the next 15 days, the samples showed a rapid disintegration. However, CS films were able to disintegrate only after five weeks [121].

\section{Starch}

For some time, starch has been highlighted as a great alternative $[10,12,30,37]$. The reasons for the interest in using starch are its low cost, biocompatibility, non-toxicity, and easy chemical modification. Clearly, among these characteristics, their chemical structure is one of the most attractive, since offers a lot of possibilities to improve or incorporate certain properties according to each particular application [20,21,31,32]. As was reviewed in Section 1 , starch has been used for different purposes, in many ways from blends to composites (Figure 5). Nowadays, given complex environmental problems is necessary to open the doors to the use of biopolymers and the properties of starch make it an excellent alternative. 


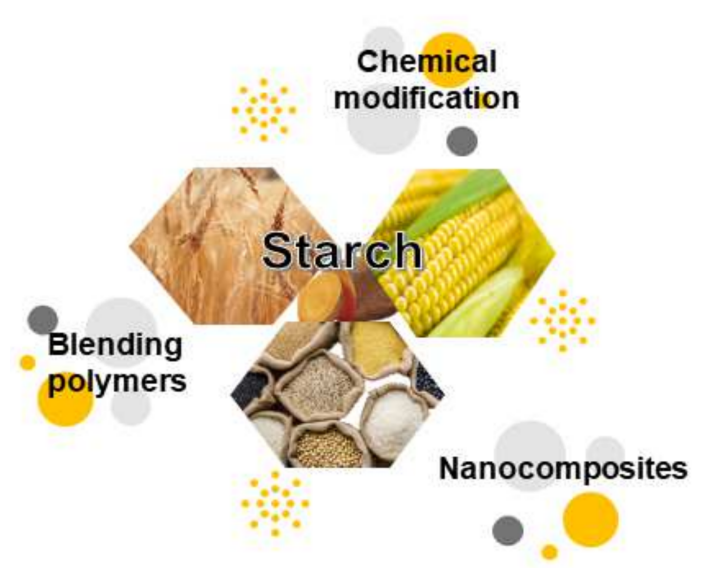

Figure 5. Use of starch as remover pollutant in different ways.

\subsection{Starch as Pollutants Remover}

Nowadays, the scarcity of water is a problem that many industries must face. Unfortunately, industrial growth causes a huge discharge of polluted water, and much of this water is not treated before disposal. Industrial water contains pesticides, heavy metals, toxic dyes, organic and inorganic pollutants, and much more. In this context, heavy metals can cause serious damage to living organisms, dramatically affecting the ecosystem of various species. In animals and humans, they can produce the disruption of enzymatic functions resulting in serious health consequences [122].

The use of adsorption as a method for removing pollutants is attractive due to its low cost, high efficiency, and easy procedures. The use of starch-whether it is chemically modified, blended, or in composites-as an alternative contaminant removal material has been studied [123-127]. Various techniques are usually developed to characterize this type of systems. Among them are adsorption studies, Fourier transform infrared spectroscopy (FT-IR), X-ray diffraction (XRD), SEM, transmission electron microscopy (TEM), and adsorption kinetics. These characterizations definitely help to understand the performance of starch as an adsorbent agent. However, in recent years, there have appeared other characterizations that could offer a larger understanding regarding the physical properties of adsorbent agents. Below, we will review some of them.

\subsection{Superficial Analysis}

\subsubsection{Energy-Dispersive Spectroscopy (EDS)}

The energy-dispersive spectroscopy technique is an experimental method that allows semi-quantitative measurement. This superficial technique is used as a complementary characterization of SEM, coupled according to sample requirements. In the study by Chen et al. [128], $\mathrm{CaCO}_{3}$ was added on the surface of starch-FBO (ferromanganese binary oxide) to form Ca-starch-FBO, aiming to improve the adsorption capacity of $\mathrm{Cd}(\mathrm{II})$ and the removal of As and $\mathrm{Cd}$ at specific $\mathrm{pH}$ conditions. The EDS results showed that the distribution of $\mathrm{Ca}$, As, and $\mathrm{Cd}$ was similar. Fe and $\mathrm{Mn}$ that were used during the treatment also were recorded. The latter might affect the adsorption of the material of interest. A ternary complex could be formed, which would affect the adsorption capacity due to competition for active sites in the adsorbent material. FT-IR corroborates this assumption.

Cellulose nanofibers (CNFs) can be used as adsorbent material. Baghbadorani et al. [15] treated cellulose nanofibers on starch-g-poly(acrylic acid) (St-g-PAA) for $\mathrm{Cu}^{2+}$ elimination in an aqueous medium. This composite improved the adsorption of ions in the study. Characteristic such as the negative charge of CNFs and their large surface area allowed the composite to reach its goal. EDS characterization was performed to confirm $\mathrm{Cu}^{2+}$ removal. They observed that there is $52.89 \mathrm{wt} \%$ on the surface of the composite prepared (Figure 6).

In another study about $\mathrm{Cu}$ removal (II) from aqueous media, Dai et al. [129] elaborated a hydrogel containing sodium alginate and 2-hydroxy-3-isopropoxypropyl starch. Once the 
hydrogel and $\mathrm{Cu}(\mathrm{II})$ were in contact, they used EDS characterization to verify the presence of $\mathrm{Cu}(\mathrm{II})$ in the hydrogel surface. The results of this technique showed that $\mathrm{Cu}$ (II) was successfully adsorbed by the hydrogel prepared. They also observed that the hydrogel maintained its signal after the adsorption of $\mathrm{Cu}$ (II). This indicates a good stability of the hydrogel used. A novel material constituted by stable starch with loaded nano zero-valent iron was developed by Yang et al. [130] to remove $\mathrm{Cr}(\mathrm{VI})$ from wastewater. They used the EDS method for studying Fe distribution. In this sense, they observed that the distribution of Fe onto stable starch was uniform.

\subsubsection{X-ray Photoelectron Spectroscopy (XPS)}

$\mathrm{X}$-ray photoelectron spectroscopy (XPS) is a compound analysis quantitative technique that measures surface elemental composition. XPS can be useful for adsorbent characterizations as it might clarify the adsorption mechanisms involved. Mittal et al. [131] developed a new magnetic adsorbent using $\mathrm{Fe}_{3} \mathrm{O}_{4}$ nanoparticles and starch as a carbon source. The deposition of nanoparticles, $\mathrm{Fe}_{3} \mathrm{O}_{4}$, onto the surface of carbonized starch was confirmed through XPS analysis. $\mathrm{Hg}^{2+}$ is a long-lasting toxic metal that causes serious damage by accumulating both in the environment and in humans. Human activities in industrial areas are responsible for this pollutant. In this regard, Naushad et al. [132] developed starch $/ \mathrm{SnO}_{2}$ nanocomposites for the removal of $\mathrm{Hg}^{2+}$ from aqueous media. Through XPS characterization, they found that the adsorption of $\mathrm{Hg}^{2+}$ was carried out at superficial level, meaning that $\mathrm{Hg}^{2+}$ was adsorbed onto the nanocomposites. They also verified that $\mathrm{Hg}^{2+}$ did not change its oxidation state.

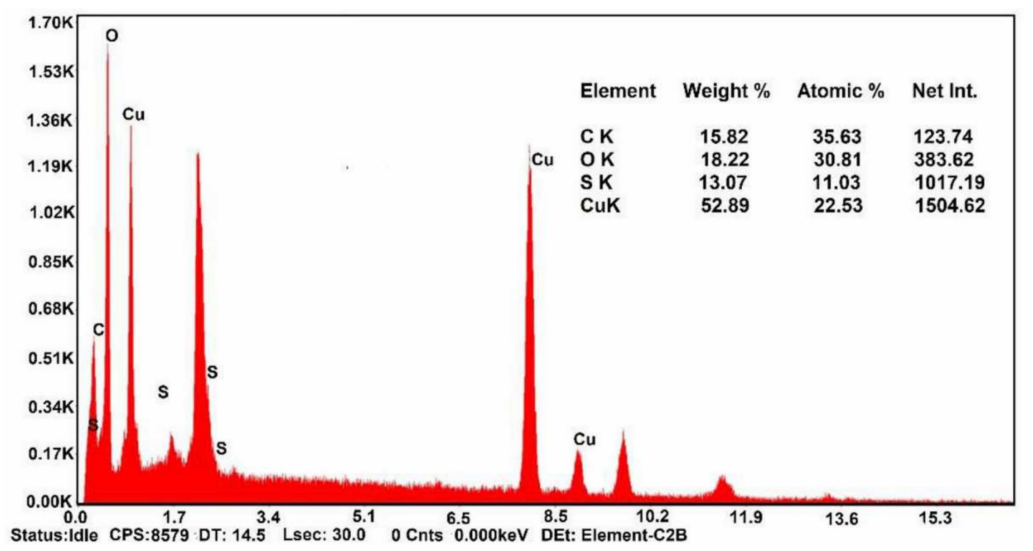

Figure 6. Energy-dispersive X-ray spectroscopy (EDX) elemental analysis of cellulose nanofiber (CNF)-treated hydrogel after ion adsorption (initial $\mathrm{Cu}^{2+}$ concentration of $0.4 \mathrm{~g} / \mathrm{L}$, adsorbent dosage of $0.3 \mathrm{~g} / \mathrm{L}$, pH level of 5). (Reprinted from ref. [15]. Copyright 2019 with permission from Elsevier).

On the other hand, mechanisms involved in adsorption can also be elucidated using the XPS technique. In this way, Fu et al. [133] developed an adsorbent from a starch-based polysulfide complex material with the aim of capturing $\mathrm{Hg}$ (II) and then converting the absorbent material into a catalyst. Through XPS, they proposed a possible mechanism of adsorption. Firstly, XPS showed that $\mathrm{Hg}$ (II) was successfully adsorbed. Then, they observed that $\mathrm{O}, \mathrm{N}$, and $\mathrm{S}$ are involved in $\mathrm{Hg}$ adsorption. The researchers proposed that several factors are involved in the adsorption of mercury such as metal chelation, complexation, and electrostatic attraction. Figure 7 details the above.

The adsorption of gold becomes interesting since this element is a non-renewable precious resource. This metal is used in several applications, mainly for electronic and catalysis applications. In this sense, there is a large amount of electronic waste containing gold that causes serious damage to the environment. Thus, Liu et al. [134] prepared a composite through a crosslinking reaction between tannin acid and dialdehyde corn starch to be used as bio-adsorbent and remove $\mathrm{Au}(\mathrm{III})$ from wastewater. The XPS technique was used to try to elucidate the mechanism of Au adsorption (III) on starch-based composite. 
They found that when the adsorbent was added into the $\mathrm{Au}(\mathrm{III})$ solution, electrostatic interactions were produced. Then, a redox reaction was carried out where hydroxyl groups of adsorbent were oxidized to carbonyl groups, while $\mathrm{Au}(\mathrm{III})$ was reduced to $\mathrm{Au}(0)$. The latter could be observed since gold particles were detected in the bio-adsorbent surface.

Xue et al. [135] developed a film consisting of CdS and carboxymethyl starch with the aim of removing certain dyes from water. In this case, they used XPS to establish what type of interaction was between CdS and modified starch (Figure 8). In this sense, they observed that CdS interacts with carboxymethyl starch (CMS) through electrostatic interactions. There is no chemical bonding involved. Based on this literature, it can be observed that the use of the XPS technique is a great complement to both verify the adsorption of the substance of interest and elucidate the adsorption mechanisms involved.

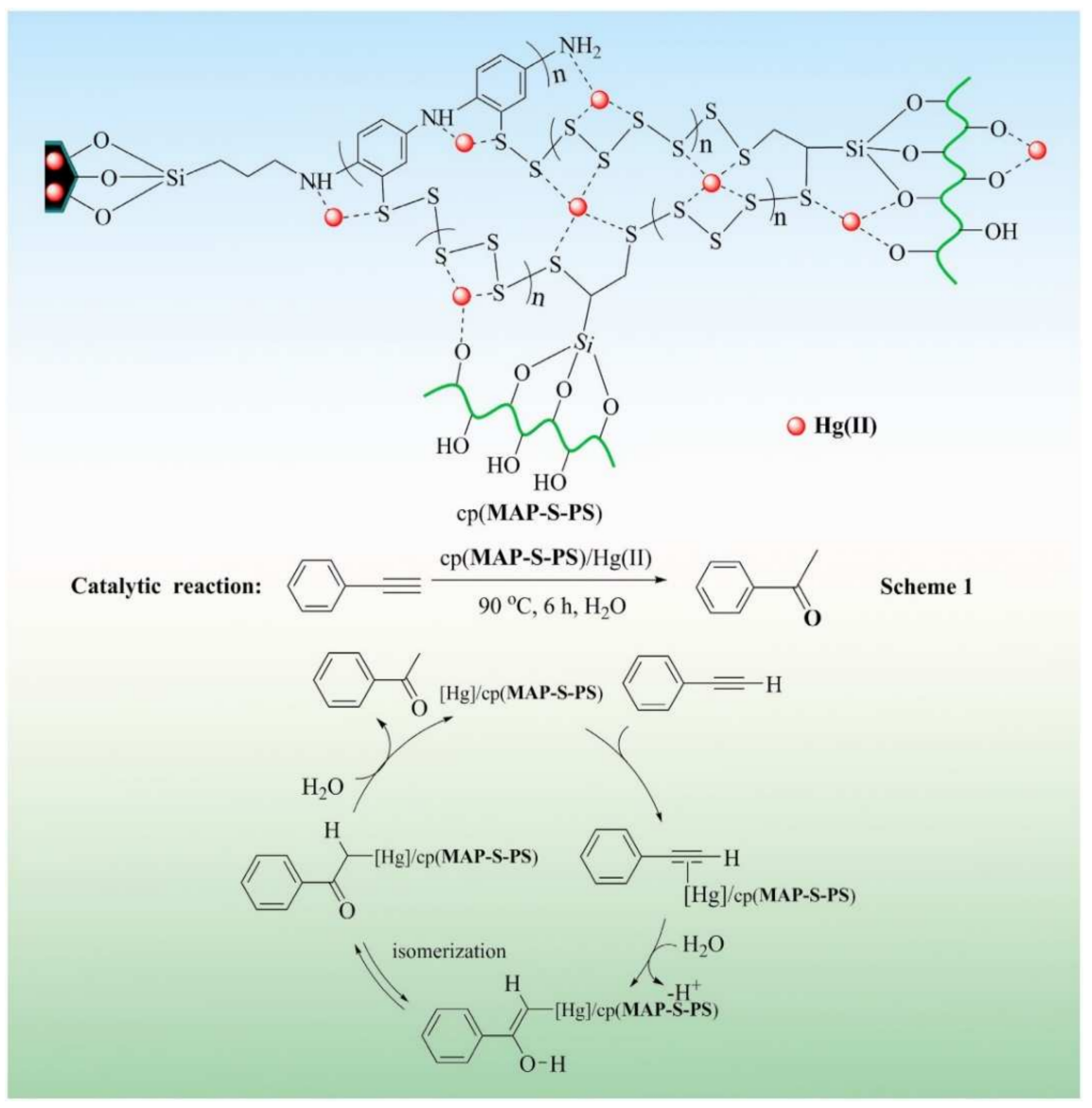

Figure 7. The adsorption mechanism of $\mathrm{Hg}$ (II) ions removed by polysulfide complex material starch based. (Reprinted from ref. [134]. Copyright 2021 with permission from Elsevier).

\subsubsection{BET (Brunauer-Emmett-Teller)}

BET (Brunauer-Emmett-Teller) theory is a method used to study the adsorption phenomena on solid surfaces. Although BET is not a new technique, its use as a complementary technique for studying pollutant adsorbent materials has increased in recent years. It certainly is a technique that should be included in the characterization of this type of material since, through this characterization, it is possible to know the porosity type of the adsorbent material and thus achieve an appropriate application. Mittal el al. [131] developed a magnetic carbonaceous adsorbent from corn starch. BET studies showed wide distribution of pore size generated in the adsorbent surface. In this study, it was observed that the magnetization involved improved the porosity with a higher surface area. Pore volume was improved too. Therefore, BET characterization allowed the observation that the porous structure of corn starch was enhanced with the incorporation of $\mathrm{Fe}_{3} \mathrm{O}_{4}$ nanoparticles for the 
adsorption of cationic dye from wastewater. In another work, Stan et al. [136] modified the starch surface with $\mathrm{Fe}_{3} \mathrm{O}_{4}$ magnetic nanoparticles prepared through an environmentally friendly synthetic route. In this work, BET results showed a higher surface area in starch with nanoparticles when compared to starch without nanoparticles. The type of porous corresponded to mesopores and the average pore size radius was $12.55 \mathrm{~nm}$.
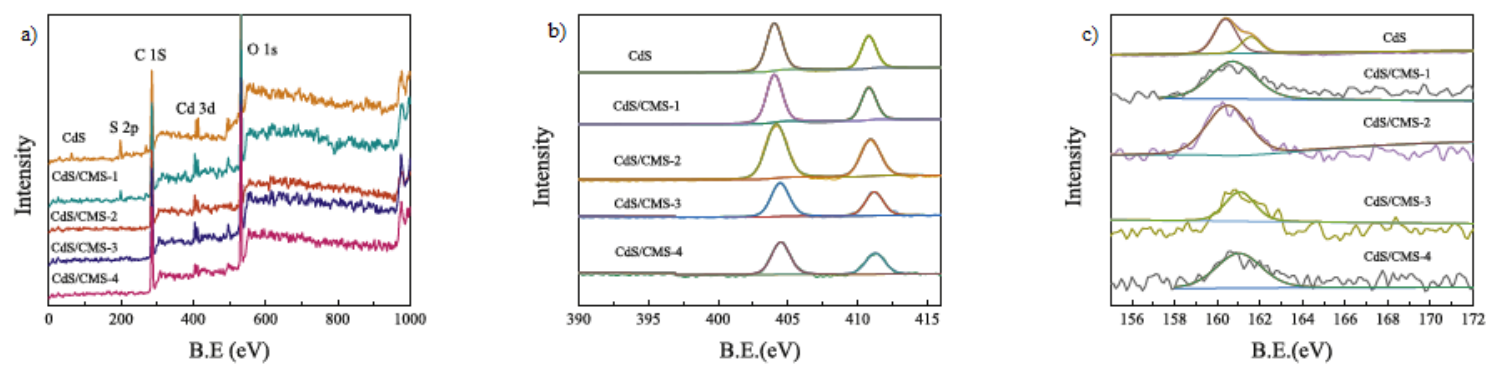

Figure 8. (a) Typical X-ray photoelectron spectroscopy (XPS) wide scan spectra, (b) Cd 3d and (c) S 2p XPS spectra of CdS, CMS, CdS/CMS-1, CdS/CMS-2, CdS/CMS-3, and CdS/CMS-4. (Reprinted from ref. [135]. Copyright 2020 with permission from Elsevier).

Furthermore, Tao et al. [123] modified starch with ZnMgAl-LDHs (LDHs: Layered double hydroxides) to improve the adsorption properties of starch. They observed that the surface area had increased, however, the excess of starch generated a collapse in the hydrotalcite structure resulting in the reduction of adsorption capacity of the material. Priyanka and Saravanakumar [124] designed a novel starch-derived zinc-carbon foam-like (Zn-CFst) material to adsorb different dyes. BET analysis indicated a highly mesoporous surface with an average pore diameter of $31 \AA$. The adsorbent efficacy markedly improved due to the pore diameter and mesoporous surface. These are both quite important for quick and efficient dye adsorption.

\subsection{Magnetic Properties}

The use of magnetic material such as nanoparticles (for instance, $\mathrm{Fe}_{3} \mathrm{O}_{4}$ ) is steadily increasing in the world of starch-based adsorbents. The purpose of this is to stabilize the tendency to aggregation of nanoparticles through the development of biopolymer coatings. In this sense, the vibrating sample magnetometer (VSM) method was used to measure the electromagnetic properties of different materials containing magnetic structures. This characterization can provide important information regarding the stability of the magnetic properties of material incorporated into starch.

In the previous section, we reviewed the work by Stan et al., [136] who developed a green remover to remove dyes using starch coated magnetic nanoparticles. Through VSM measurements, they observed that the saturation magnetization values decreased regarding non-stabilized $\mathrm{Fe}_{3} \mathrm{O}_{4}$. This result could be attributed to the starch coat. Meanwhile, lower saturation magnetization values were observed after the adsorption of dye. Aiming for water remediation, Perez et al. [137] developed a material based on manganese ferrite $\left(\mathrm{MnFe}_{2} \mathrm{O}_{4}\right)$ nanoparticles covered with starch. Magnetization measurements of the starchcoated $\mathrm{MnFe}_{2} \mathrm{O}_{4}$ showed a decrease in saturation magnetization regarding $\mathrm{MnFe}_{2} \mathrm{O}_{4}$ nanoparticles, which could be due to functionalization with starch.

Starch-stabilized zero-valent iron nanoparticles were synthesized by Okuo et al. [138] with the purpose of being used as potential synthetic immobilizing agents in the remediation of soils contaminated with $\mathrm{Pb}, \mathrm{Cr}, \mathrm{Ni}$, and $\mathrm{Cd}$. VSM analysis showed that starchstabilized zero-valent iron nanoparticles were superparamagnetic. This characteristic indicates the great stability of this material, both thermally and chemically.

Gong et al. [139] developed magnetite $\left(\mathrm{Fe}_{3} \mathrm{O}_{4}\right)$ nanoparticles using starch as stabilizer for the removal of aqueous perfluorooctanoic acid (PFOA). This acid is widely used in manufacturing industry. Unfortunately, it is a species listed as persistent, being detected 
both in the environment and human beings. PFOA shows bioaccumulation, toxicity, and resistance to typical environmental degradation processes. The magnetic properties of nonstabilized and starch-stabilized magnetite were measured. The saturation magnetization value was lower in starch-stabilized $\mathrm{Fe}_{3} \mathrm{O}_{4}$ than in non-stabilized $\mathrm{Fe}_{3} \mathrm{O}_{4}$. They attributed this difference to the size effects. The surface/volume rate of starch-stabilized nanoparticles is large, which could have structural effects resulting in magnetic differences between starch-stabilized $\mathrm{Fe}_{3} \mathrm{O}_{4}$ and non-stabilized $\mathrm{Fe}_{3} \mathrm{O}_{4}$.

Another study worked with $\mathrm{Fe}_{3} \mathrm{O}_{4}$ nanoparticles using starch-salicylaldehyde based nanocomposites and salicylaldehyde resin as stabilizer for their potential application as $\mathrm{Pb}$ (II) and $\mathrm{Cd}$ (II) adsorbents in aqueous solutions [122]. VSM characterization showed, as we have seen previously, that the saturation magnetization value in stabilized- $\mathrm{Fe}_{3} \mathrm{O}_{4}$ nanoparticles is lower than in non-stabilized- $\mathrm{Fe}_{3} \mathrm{O}_{4}$ nanoparticles. These results indicate that the magnetic properties in stabilized- $\mathrm{Fe}_{3} \mathrm{O}_{4}$ nanoparticles nanocomposites are still valid and can be removed from the matrix after the adsorption process. The use of magnetic adsorbents for the removal of aqueous pollutants has gained attention as it allows for their easy separation through the application of a magnetic field. In general, in the studies reviewed, it can be observed that the magnetic properties of the nanoparticles used were maintained.

\subsection{Molecular Dynamics (MD) Simulation}

Molecular dynamics is a computational simulation technique developed through approximations of known physics in which both atoms and molecules interact over a period, giving a vision of the movement of the particles. These simulations are frequently used in research related to proteins and biomolecules, as well as other materials studied by science.

One of the investigations in this area is the work carried out by Mofradnia et al. [140], who studied the efficacy of starch-modified zero-valence iron nanostructure for nitrate removal. They simulated the effect of zero-valence iron/starch nanoparticles in contact with Thiobacillus dinitrificans for the removal of nitrates, using materials study software, based on thermodynamic principles and appropriate equations, through a simulation of molecular dynamics.

For the optimization of the work, the structure of Thiobacillus denitrificans, they suggest extracting it from the RCSB (Research Collaboratory for Structural Bioinformatics) database, doi:10.2210/pdb3sb1/pdb. On the other hand, nitrate structures and starch molecules they since from the PubChem molecular bank. Subsequently, they added starch molecules to zero valence iron nanoparticles with the intention of increasing the stability of the adsorbent and preventing the oxidation of the nanoparticles. With this they found that the starch fulfils a membrane function for the surface of the iron nanoparticles, also protecting the structure of the nanoparticles closest between the microorganism and the zero-valence iron nanostructure. This caused the reactivity of the nanoparticles to increase when starch molecules are added for the elimination of nitrates.

The structures designed them based on microorganisms in an aqueous medium, where the accumulation of its components was carried out through a module of amorphous cells tools and a compass force field at a constant pressure of $101.325 \mathrm{kPa}$ and a temperature of $298 \mathrm{~K}$. On the other hand, the percentage ratio was $45.3 \%$ nitrate and $54.7 \%$ water. In addition, they used the periodic boundary conditions (PBC) for the proper distribution of the components in the box and the unwanted parameters were optimized to 10,000 energy units.

For the final investigation of molecular dynamics, they used the Forcite module with the dynamic operating tool and the compass force field. To avoid computational interference, they suggest that the system be neutralized early in the process. The calculations were simulated at constant temperature using the NVT computational equation and the Nosé-Hoover equation (NHL), where they selected an adequate temperature control based on the presence of nanoparticles in the system. To condition the system to simulate the 
experimental conditions, they established that all parts of the system were at ambient pressure. Each of the steps were performed at 5 ps and the calculations at $1 \mathrm{fs}$ intervals.

To present the results of the predictions made in this research, they conducted studies based on radial distribution (RDF), density, potential energy, and temperature. One of these results showed the simultaneous increase in nitrate removal efficiency when the zero-valence iron/starch nanoparticles and Thiobacillus dinitrificans were present, reaching $91 \%$, compared to when there were no nanoparticles in the system, reaching only $44.44 \%$, verifying that the removal of nitrates increased considerably with the presence of nanoparticles, also increasing the stability of the system. Then, the extracted results indicated that the density reached $1.65 \mathrm{~g} / \mathrm{cm}^{3}$ in the presence of the nanoparticle, much higher than that calculated in the absence, reaching a value of $0.82 \mathrm{~g} / \mathrm{cm}^{3}$.

Another work that used a molecular dynamics (MD) simulation was carried out by Cui et al. [141], where they simulated the relationships between the mixtures of starch, urea and water using GROMACS 5.1.4. They introduced a starch fragment containing 55 glucose residues, with structures similar to a helix, to simulate the real structure of starch and represent its characteristics and properties, saving computational resources.

On the other hand, the glucose force field was modified from the OPLSAA (Optimized Potentials for Liquid Simulations all atom) force field for carbohydrates, suitable for the model molecule [142]. To carry out the study and have the appropriate coordinates, they requested the molecular model and the force field from the Shanghai Institute of Technology (Shanghai, China). As for the pdb (Protein Data Bank) file (Protein Data Bank), they use the urea topology file they were generated through the LigParGen server with OPLSAA force field [142-145], using the TIP4P (Transferable intermolecular potential with four points) water model. In all simulations, the molecular model was incorporated in the center of a $9 \times 9 \times 9 \mathrm{~nm}^{3}$ cubic box with periodic boundary, where the system contained $0,900,1900$, 2900 and 3900 urea molecules. They set the Lennard-Jones potential truncation radius to $1 \mathrm{~nm}$, and constrained all link lengths using the LINCS (Linear Constraint Solver) algorithm.

Regarding the short-range electrostatic interaction, in addition to the van der Waals interaction, these were handled at $1 \mathrm{~nm}$, and to calculate the long-range interaction the Ewald particle mesh method (PME) was adopted. Regarding the temperature, they set it at $300 \mathrm{~K}$ and the pressure at $1 \mathrm{~atm}$ using the Parrinello-Rahman barostat [146]. To observe the positions, velocities and energies, a record was made every $10.0 \mathrm{ps}$.

The most important results of this research are the significant change experienced by the structure and morphology, as well as the thermal property of starch in the presence of urea, showing that it depends positively on the urea content of aqueous solutions.

Regarding the molecular dynamics' simulations, the study focused on the interaction of hydrogen bonds, in the distribution of starch, urea and water fragments, both at the molecular and atomic level. Noting that the hydroxyl oxygen atoms in the glucose residue, the nitrogen atoms in the urea molecule and as well as the oxygen atom present in the water molecule are the main hydrogen bonding sites between the solute and the solvent.

On the other hand, they also observed that urea molecules replaced the place of certain water molecules due to the formation of hydrogen bonds with the hydroxyl oxygen atoms of the starch, altering the water network around the starch molecule. Therefore, this study provided important information on the phase transitions of starch in aqueous medium. They concluded that this simulation could potentially be used to design starchcontaining materials.

\subsection{Electronic Structure}

Another potential use of computational studies is through functional density theory (DFT), which is applied to electronic systems. This an alternative variational procedure to the solution of the Schrödinger equation, where the functionality of electronic energy is minimized with respect to electronic density. This method is currently one of the most widely used for work on quantum calculations of the electronic structure of matter, especially in research on the physics of condensed matter, as well as quantum chemistry. 
One of the works that used this method was carried out by Bashir et al. [147], who synthesized a polymer of potato starch phosphate (PSP) using ultrasound microwaves, which they carried out by crosslinking the hydroxyl groups of native potato starch (NPS) and using phosphoryl chloride as a crosslinking agent. In this theoretical-experimental investigation, a study was carried out on the selectivity of metal ions, and the sorption mechanism.

To validate the experimental selectivity and further investigate the chemical interactions between the $\mathrm{Zn}(\mathrm{II}), \mathrm{Cd}(\mathrm{II}), \mathrm{Pb}$ (II) and $\mathrm{Hg}$ (II) ions and the biosorbent PSP, DFT incorporated in the Gaussian code set 03 [148]. To optimize the geometries of the molecules they used Becke's three-parameter hybrid model, using the Lee-Yang-Parr (B3LYP) and LanL2DZ set of functional correlation bases $[149,150]$. To simulate chemical selectivity, they used a cross-linked starch fragment as a model for computational details. The particularity is that in the chosen fragment, there were abundant hydroxyl groups available for the attachment of metal ions, including surface hydroxyls, glycosidic hydroxyls, and phosphate hydroxyls.

To perform the load study, these researchers performed a Mulliken load analysis, which allows the measurement of elemental load. As a result, they observed that oxygen phosphate atoms carry more negative partial charges than terminal oxygen or glycosidic oxygen, suggesting that oxygen phosphate is a more favourable site for adsorption of metal cations. The above allowed them to optimize the geometries of the PSP- $\mathrm{M}^{2+}$ cluster models, where the cation, $\mathrm{M}^{2+}(\mathrm{M}=\mathrm{Zn}, \mathrm{Pb}, \mathrm{Cd}$ and $\mathrm{Hg})$, binds to the oxygen phosphate atoms in an optimized structure. On the other hand, the binding energy values (Ebd) were calculated as Ebd, where the positive values obtained indicated that the adsorption was favourable and the interaction was stable [151].

Another important step was the calculation that they made to the binding energy values for the $\mathrm{Zn}(\mathrm{II}), \mathrm{Cd}(\mathrm{II}), \mathrm{Pb}(\mathrm{II})$ and $\mathrm{Hg}$ (II) ions. The DFT calculations showed that PSP exhibits the strongest adsorption selectivity towards $\mathrm{Zn}$ (II) among all the heavy metal ions tested. This result agreed with the paradigm of Pearson's HSAB (Hard soft acids bases) principle, where it is estimated that the border "cations $\mathrm{Zn}$ (II) and $\mathrm{Pb}$ (II) interact more strongly with the hard anion $\left(\mathrm{O}^{-}\right)$and, consequently, the soft cations $(\mathrm{Cd}(\mathrm{II}))$ and $\mathrm{Hg}(\mathrm{II}))$ interact less [149]. These quantum calculations using density functional theory (DFT) supported experimental results of adsorption selectivity that $\mathrm{Zn}$ (II) $>\mathrm{Pb}$ (II) $>\mathrm{Cd}$ (II) $>\mathrm{Hg}(\mathrm{II})$, in terms of bond energy measurements metal-oxygen.

\subsection{Reusability}

The recyclability of the adsorbent is quite an important factor for it to have feasible applications. In this sense, the stability of the adsorbent is key to achieve this property, and the total cost of the adsorbent will be an important advantage. Adsorbent reusability is absolutely necessary in the recycling context. The fact that a material can be used more than once causes a positive impact on the environment. On the subject of the physical properties of adsorbents, this characterization can provide important information about the conformation of the material and its stability.

Through reusability tests, Ahamad et al. [122] showed that their adsorbent could be reused until 5 cycles regarding $\mathrm{Pb}$ (II) and $\mathrm{Cd}$ (II) adsorption (Figure 9). After seven cycles, there was a slow decrease in the adsorption capacity of these metals. In the previous section, we saw that they developed this adsorbent using starch-salicylaldehyde nanocomposites. Similarly, in 2020, Perez et al. [137] presented an adsorbent based on magnetite nanoparticles $\left(\mathrm{Fe}_{3} \mathrm{O}_{4}\right)$ stabilized with carboxymethylated starch. Reusability was observed even after 4 cycles of $\mathrm{Pb}$ (II) removal. 


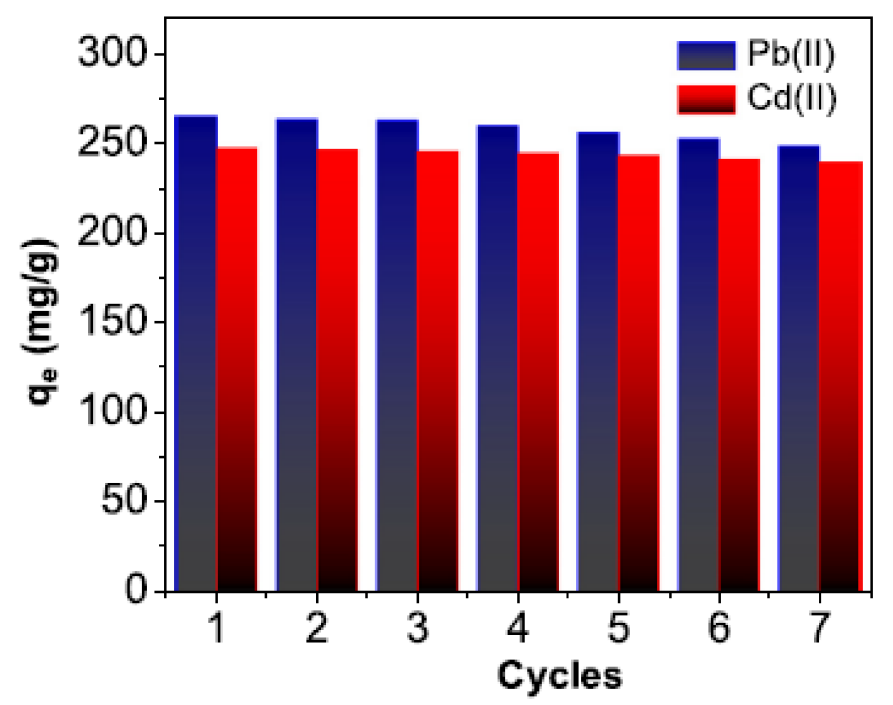

Figure 9. Reusability cycles of for the adsorption of $\mathrm{Pb}$ (II) and $\mathrm{Cd}(\mathrm{II})$ over starch-salicylaldehyde nanocomposites ( $2 \mathrm{mg}$, in $25 \mathrm{~mL}$ volume, time $60 \mathrm{~min}$ and the initial concentration $50 \mathrm{ppm}$ ). (Reprinted from ref. [122]. Copyright 2020 with permission from Elsevier).

Mittal et al. [131] introduced an adsorbent prepared with magnetized and starch-based carbonaceous material. This material was used to study methyl blue removal. Herein, the results of reusability tests showed that, throughout six cycles of adsorption-desorption, there was good efficiency of above $90 \%$. Figure 10 shows the reusability test performed by Suo et al. [152]. They developed a mesoporous activated carbon adsorbent from starch to remove pesticides from water. They found that, after five consecutive cycles of adsorptiondesorption, the adsorption efficiency of 11 pesticides was over $80 \%$.

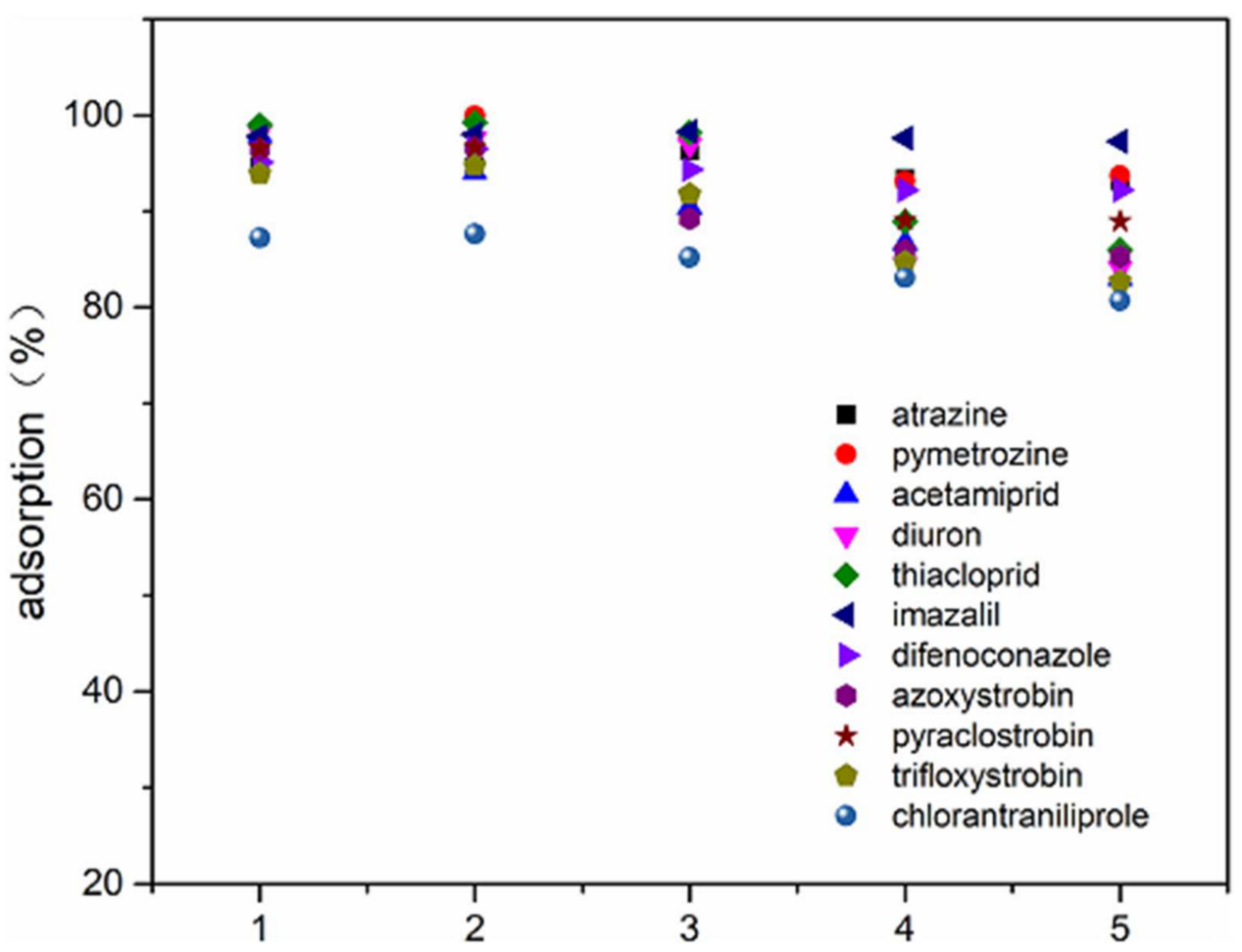

Figure 10. Adsorption efficiency of 11 pesticides by adsorbent mesoporous activated carbon from starch after various cycles of regeneration. (Reprinted from ref. [152]. Copyright 2019 with permission from Elsevier). 
In general, an excellent adsorption efficiency is observed in starch-based materials. This characterization indicates great chemical and physical stability, exhibiting high efficiency in up to five cycles of adsorption.

\section{Overview}

The use of biopolymers in several areas, such as the replacement of conventional polymers, is a challenge. Chitosan and starch present attractive physical and chemical properties, which make them excellent alternatives for this change. The use of these biopolymers, either through the mixing with other polymers, the formation of composites, or the chemical modification, allows an improved material with the desired properties to be obtained.

In the food packaging industry, chitosan is an excellent candidate to replace conventional polymers because it exhibits a great capability to form films with suitable mechanical properties such as stress-resistant, flexibility, and elasticity properties, and on the other hand, antimicrobial activity. The packaging industry attaches great importance to protecting the food and making it attractive for customers. In this sense, advancements in packaging ensure the quality of food products inside the packaging, regarding shelf life and usability, to the customers. Meanwhile, in the field of aqueous pollutant removal, starch is in high demand due to its characteristics, i.e., being biocompatible, affordable, and chemically attractive. In this review, we have identified some highlighted characterizations concerning chitosan in the food packaging field and starch in the pollutant removal field, such as mechanical, thermal, optical, barrier, biodegradability, reusability, molecular simulation electronic structure, superficial, and magnetic properties characterization. All these characterizations give us necessary and complementary information to better understand the properties of these biopolymers in the respective areas reviewed.

Author Contributions: Conceptualization, N.A.; Methodology, N.A., R.L.A. and C.L.-F.; Software, N.A., R.L.A. and C.L.-F.; Validation, N.A., R.L.A. and C.L.-F.; Formal Analysis, N.A., R.L.A. and C.L.F.; Investigation, N.A., R.L.A. and C.L.-F.; Data Curation, N.A., R.L.A. and C.L.-F.; Writing-Original Draft Preparation, N.A., R.L.A. and C.L.-F.; Writing-Review and Editing, N.A. All authors have read and agreed to the published version of the manuscript.

Funding: This research (C.L.-F.) was funded by CONICYT + PAI Convocatoria Nacional Subvención a la Instalación Académica, Convocatoria 2017, PAI77170033.

Institutional Review Board Statement: Not applicable.

Informed Consent Statement: Not applicable.

Data Availability Statement: Not applicable.

Conflicts of Interest: The authors declare no conflict of interest.

\section{References}

1. Priyadarshi, R.; Rhim, J.W. Chitosan-based biodegradable functional films for food packaging applications. Innov. Food Sci. Emerg. Technol. 2020, 62, 102346-102365. [CrossRef]

2. Méité, N.; Konan, L.K.; Tognonvi, M.T.; Doubi, B.I.H.G.; Gomina, M.; Oyetola, S. Properties of hydric and biodegradability of cassava starch-based bioplastics reinforced with thermally modified kaolin. Carbohydr. Polym. 2021, 254, 117322-117330. [CrossRef] [PubMed]

3. Su, L.; Huang, J.; Li, H.; Pan, Y.; Zhu, B.; Zhao, Y.; Liu, H. Chitosan-riboflavin composite film based on photodynamic inactivation technology for antibacterial food packaging. Int. J. Biol. Macromol. 2021, 172, 231-240. [CrossRef]

4. FAO. Fishery and Aquaculture Statistics 2018/FAO Annuaire. Statistiques des Pêches et de L'aquaculture 2018/ FAO Anuario. Estadísticas de Pesca y Acuicultura 2018; FAO: Rome, Italy, 2020.

5. FAO. Available online: http://www.fao.org/faostat/en/\#data (accessed on 2 April 2021).

6. Jorge Gonçalves, F.; Alves Gurgel, L.V.; Catone Soares, L.; Simões Teodoro, F.; Dias Ferreira, G.M.; Coelho, Y.L.; Mendes da Silva, L.H.; Prim, D.; Gil, L.F. Application of pyridine-modified chitosan derivative for simultaneous adsorption of $\mathrm{Cu}(\mathrm{II})$ and oxyanions of $\mathrm{Cr}(\mathrm{VI})$ from aqueous solution. J. Environ. Manag. 2021, 282, 111939-111957. [CrossRef] [PubMed] 
7. Mohammed, L.; Nourddine, H.; Saad, E.F.; Abdelali, D.; Hamid, R. Chitosan-covered liposomes as a promising drug transporter: Nanoscale investigations. RSC Adv. 2021, 11, 1503-1516. [CrossRef]

8. Wang, M.; Li, L.; Wan, M.; Lin, Y.; Tong, Y.; Cui, Y.; Deng, H.; Tan, C.; Kong, Y.; Meng, X. Preparing, optimising, and evaluating chitosan nanocapsules to improve the stability of anthocyanins from Aronia melanocarpa. RSC Adv. 2021, 11, 210-218. [CrossRef]

9. Leonardi, M.; Caruso, G.M.; Carroccio, S.C.; Boninelli, S.; Curcuruto, G.; Zimbone, M.; Allegra, M.; Torrisi, B.; Ferlito, F.; Miritello, M. Smart nanocomposites of chitosan/alginate nanoparticles loaded with copper oxide as alternative nanofertilizers. Environ. Sci. Nano 2021, 8, 174-187. [CrossRef]

10. Mahmoud, M.E.; Fekry, N.A.; Abdelfattah, A.M. Removal of uranium (VI) from water by the action of microwave-rapid green synthesized carbon quantum dots from starch-water system and supported onto polymeric matrix. J. Hazard. Mater. 2020, 397, 122770-122784. [CrossRef]

11. Sancey, B.; Trunfio, G.; Charles, J.; Minary, J.F.; Gavoille, S.; Badot, P.M.; Crini, G. Heavy metal removal from industrial effluents by sorption on cross-linked starch: Chemical study and impact on water toxicity. J. Environ. Manag. 2011, 92, 765-772. [CrossRef]

12. Lozano-Morales, V.; Gardi, I.; Nir, S.; Undabeytia, T. Removal of pharmaceuticals from water by clay-cationic starch sorbents. J. Clean. Prod. 2018, 190, 703-711. [CrossRef]

13. Farag, A.M.; Sokker, H.H.; Zayed, E.M.; Nour Eldien, F.A.; Abd Alrahman, N.M. Removal of hazardous pollutants using bifunctional hydrogel obtained from modified starch by grafting copolymerization. Int. J. Biol. Macromol. 2018, 120, 2188-2199. [CrossRef]

14. Abid, R.K.; Abbas, A.S. Adsorption of organic pollutants from real refinery wastewater on prepared cross-linked starch by epichlorohydrin. Data Br. 2018, 19, 1318-1326. [CrossRef]

15. Bahadoran Baghbadorani, N.; Behzad, T.; Etesami, N.; Heidarian, P. Removal of Cu2+ ions by cellulose nanofibers-assisted starch-g-poly(acrylic acid) superadsorbent hydrogels. Compos. Part B Eng. 2019, 176, 107084-107093. [CrossRef]

16. Debnath, S.; Maity, A.; Pillay, K. Magnetic chitosan-GO nanocomposite: Synthesis, characterization and batch adsorber design for Cr(VI) removal. J. Environ. Chem. Eng. 2014, 2, 963-973. [CrossRef]

17. Rajabi, H.; Jafari, S.M.; Feizy, J.; Ghorbani, M.; Mohajeri, S.A. Preparation and characterization of 3D graphene oxide nanostructures embedded with nanocomplexes of chitosan- gum Arabic biopolymers. Int. J. Biol. Macromol. 2020, 162, 163-174. [CrossRef]

18. Kucuk, A.C.; Urucu, O.A. Silsesquioxane-modified chitosan nanocomposite as a nanoadsorbent for the wastewater treatment. React. Funct. Polym. 2019, 140, 22-30. [CrossRef]

19. Bergel, B.F.; Leite Araujo, L.; dos Santos da Silva, A.L.; Campomanes Santana, R.M. Effects of silylated starch structure on hydrophobization and mechanical properties of thermoplastic starch foams made from potato starch. Carbohydr. Polym. 2020, 241, 116274-116282. [CrossRef]

20. Zhan, F.; Li, J.; Youssef, M.; Li, B. Enhancement of foam stability parallel with foamability of the foam stabilized by sodium caseinate-based complex: Octenyl succinate starch acting a dual role. Food Hydrocoll. 2021, 113, 106479-106492. [CrossRef]

21. Ji, W.; Wang, D.; Guo, J.; Fei, B.; Gu, X.; Li, H.; Sun, J.; Zhang, S. The preparation of starch derivatives reacted with urea-phosphoric acid and effects on fire performance of expandable polystyrene foams. Carbohydr. Polym. 2020, 233, 115841-115850. [CrossRef] [PubMed]

22. El-Dib, F.I.; Eshaq, G.; ElMetwally, A.E.; Hefni, H.H.H. Enhancing the porous structure of swellable poly(acrylic acid-coacrylamide) crosslinked by N-Maleyl chitosan via introducing foaming agents and non-ionic surfactant. Adv. Ind. Eng. Polym. Res. 2021, 4, 9-18.

23. Qin, H.; Wang, K. Study on preparation and performance of PEG-based polyurethane foams modified by the chitosan with different molecular weight. Int. J. Biol. Macromol. 2019, 140, 877-885. [CrossRef]

24. da Rosa Schio, R.; da Rosa, B.C.; Gonçalves, J.O.; Pinto, L.A.A.; Mallmann, E.S.; Dotto, G.L. Synthesis of a bio-based polyurethane/chitosan composite foam using ricinoleic acid for the adsorption of Food Red 17 dye. Int. J. Biol. Macromol. 2019, 121, 373-380. [CrossRef]

25. Wang, Y.; Cen, C.; Chen, J.; Fu, L. MgO/carboxymethyl chitosan nanocomposite improves thermal stability, waterproof and antibacterial performance for food packaging. Carbohydr. Polym. 2020, 236, 116078-116084. [CrossRef]

26. Zou, Y.; Zhang, C.; Wang, P.; Zhang, Y.; Zhang, H. Electrospun chitosan/polycaprolactone nanofibers containing chlorogenic acid-loaded halloysite nanotube for active food packaging. Carbohydr. Polym. 2020, 247, 116711-116720. [CrossRef] [PubMed]

27. Min, T.; Zhu, Z.; Sun, X.; Yuan, Z.; Zha, J.; Wen, Y. Highly efficient antifogging and antibacterial food packaging film fabricated by novel quaternary ammonium chitosan composite. Food Chem. 2020, 308, 125682-125689. [CrossRef] [PubMed]

28. Haghighi, H.; Leugoue, S.K.; Pfeifer, F.; Siesler, H.W.; Licciardello, F.; Fava, P.; Pulvirenti, A. Development of antimicrobial films based on chitosan-polyvinyl alcohol blend enriched with ethyl lauroyl arginate (LAE) for food packaging applications. Food Hydrocoll. 2020, 100, 105419-105429. [CrossRef]

29. Zhao, J.; Wei, F.; Xu, W.; Han, X. Enhanced antibacterial performance of gelatin/chitosan film containing capsaicin loaded MOFs for food packaging. Appl. Surf. Sci. 2020, 510, 1-9. [CrossRef]

30. Menzel, C. Improvement of starch films for food packaging through a three-principle approach: Antioxidants, cross-linking and reinforcement. Carbohydr. Polym. 2020, 250, 1-7. [CrossRef] [PubMed]

31. Kanatt, S.R. Irradiation as a tool for modifying tapioca starch and development of an active food packaging film with irradiated starch. Radiat. Phys. Chem. 2020, 173, 108873-108879. [CrossRef] 
32. Gutiérrez, T.J.; Valencia, G.A. Reactive extrusion-processed native and phosphated starch-based food packaging films governed by the hierarchical structure. Int. J. Biol. Macromol. 2021, 172, 439-451. [CrossRef]

33. Shahabi-Ghahfarrokhi, I.; Babaei-Ghazvini, A. Using photo-modification to compatibilize nano-ZnO in development of starchkefiran-ZnO green nanocomposite as food packaging material. Int. J. Biol. Macromol. 2019, 124, 922-930. [CrossRef]

34. Shakeran, Z.; Keyhanfar, M.; Varshosaz, J.; Sutherland, D.S. Biodegradable nanocarriers based on chitosan-modified mesoporous silica nanoparticles for delivery of methotrexate for application in breast cancer treatment. Mater. Sci. Eng. C 2021, 118, 111526-111544. [CrossRef]

35. Panwar, V.; Sharma, A.; Thomas, J.; Chopra, V.; Kaushik, S.; Kumar, A.; Ghosh, D. In-vitro and In-vivo evaluation of biocompatible and biodegradable calcium-modified carboxymethyl starch as a topical hemostat. Materialia 2019, 7, 100373-100386. [CrossRef]

36. Poddar, D.; Jain, P.; Rawat, S.; Mohanty, S. Influence of varying concentrations of chitosan coating on the pore wall of polycaprolactone based porous scaffolds for tissue engineering application. Carbohydr. Polym. 2021, 259, 117501-117512. [CrossRef] [PubMed]

37. Davachi, S.M.; Shiroud Heidari, B.; Hejazi, I.; Seyfi, J.; Oliaei, E.; Farzaneh, A.; Rashedi, H. Interface modified polylactic acid/starch/poly $\varepsilon$-caprolactone antibacterial nanocomposite blends for medical applications. Carbohydr. Polym. 2017, 155, 336-344. [CrossRef] [PubMed]

38. Drabczyk, A.; Kudłacik-Kramarczyk, S.; Tyliszczak, B.; Rudnicka, K.; Urbaniak, M.; Michlewska, S.; Królczyk, J.B.; Gajda, P.; Pielichowski, K. Measurement methodology toward determination of structure-property relationships in acrylic hydrogels with starch and nanogold designed for biomedical applications. Meas. J. Int. Meas. Confed. 2020, 156, 107608-107619. [CrossRef]

39. Pita-López, M.L.; Fletes-Vargas, G.; Espinosa-Andrews, H.; Rodríguez-Rodríguez, R. Physically cross-linked chitosan-based hydrogels for tissue engineering applications: A state-of-the-art review. Eur. Polym. J. 2021, 145, 110176-110196. [CrossRef]

40. Ding, S.; Wang, Y.; Li, J.; Chen, S. Progress and prospects in chitosan derivatives: Modification strategies and medical applications. J. Mater. Sci. Technol. 2020. [CrossRef]

41. Wang, Y.; Cao, H.; Wang, X. Synthesis and characterization of an injectable $\varepsilon$-polylysine/carboxymethyl chitosan hydrogel used in medical application. Mater. Chem. Phys. 2020, 248, 122902-122913. [CrossRef]

42. Deng, P.; Chen, J.; Yao, L.; Zhang, P.; Zhou, J. Thymine-modified chitosan with broad-spectrum antimicrobial activities for wound healing. Carbohydr. Polym. 2021, 257, 117630-117640. [CrossRef]

43. Mendes, J.F.; Paschoalin, R.T.; Carmona, V.B.; Sena Neto, A.R.; Marques, A.C.P.; Marconcini, J.M.; Mattoso, L.H.C.; Medeiros, E.S.; Oliveira, J.E. Biodegradable polymer blends based on corn starch and thermoplastic chitosan processed by extrusion. Carbohydr. Polym. 2016, 137, 452-458. [CrossRef] [PubMed]

44. Kumar, R.; Rahman, H.; Ranwa, S.; Kumar, A.; Kumar, G. Development of cost effective metal oxide semiconductor based gas sensor over flexible chitosan/PVP blended polymeric substrate. Carbohydr. Polym. 2020, 239, 1-7. [CrossRef]

45. Hari Gopi, K.; Dhavale, V.M.; Bhat, S.D. Development of polyvinyl alcohol/chitosan blend anion exchange membrane with mono and di quaternizing agents for application in alkaline polymer electrolyte fuel cells. Mater. Sci. Energy Technol. 2019, 2, 194-202. [CrossRef]

46. Haque, S.E.; Sheela, A. Miscibility of eudragit/chitosan polymer blend in water determined by physical property measurements. Int. J. Pharm. 2013, 441, 648-653. [CrossRef] [PubMed]

47. Jessop, I.; Albornoz, J.; Ramírez, O.; Durán, B.; Molero, L.; Bonardd, S.; Kortaberria, G.; Diaz, D.; Leiva, A.; Saldías, C. Optical, morphological and photocatalytic properties of biobased tractable films of chitosan/donor-acceptor polymer blends. Carbohydr. Polym. 2020, 249, 116822-116832. [CrossRef] [PubMed]

48. Tabasum, S.; Younas, M.; Zaeem, M.A.; Majeed, I.; Majeed, M.; Noreen, A.; Iqbal, M.N.; Zia, K.M. A review on blending of corn starch with natural and synthetic polymers, and inorganic nanoparticles with mathematical modeling. Int. J. Biol. Macromol. 2019, 122, 969-996. [CrossRef] [PubMed]

49. Singh, R.P.; Pandey, J.K.; Rutot, D.; Degée, P.; Dubois, P. Biodegradation of poly(E-caprolactone)/starch blends and composites in composting and culture environments: The effect of compatibilization on the inherent biodegradability of the host polymer. Carbohydr. Res. 2003, 338, 1759-1769. [CrossRef]

50. Sen, A.; Bhattacharya, M.; Stelson, K.A.; Voller, V.R. Creep in injection molded starch/synthetic polymer blends. Mater. Sci. Eng. A 2002, 338, 60-69. [CrossRef]

51. Costa, N.N.; de Faria Lopes, L.; Ferreira, D.F.; de Prado, E.M.L.; Severi, J.A.; Resende, J.A.; de Paula Careta, F.; Ferreira, M.C.P.; Carreira, L.G.; de Souza, S.O.L.; et al. Polymeric films containing pomegranate peel extract based on PVA/starch/PAA blends for use as wound dressing: In vitro analysis and physicochemical evaluation. Mater. Sci. Eng. C 2020, 109, 110643-110655. [CrossRef]

52. Sarkar, A.; Biswas, D.R.; Datta, S.C.; Dwivedi, B.S.; Bhattacharyya, R.; Kumar, R.; Bandyopadhyay, K.K.; Saha, M.; Chawla, G.; Saha, J.K.; et al. Preparation of novel biodegradable starch/poly(vinyl alcohol)/bentonite grafted polymeric films for fertilizer encapsulation. Carbohydr. Polym. 2021, 259, 117679-117690. [CrossRef]

53. Yaqubi, O.; Tai, M.H.; Mitra, D.; Gerente, C.; Neoh, K.G.; Wang, C.H.; Andres, Y. Adsorptive removal of tetracycline and amoxicillin from aqueous solution by leached carbon black waste and chitosan-carbon composite beads. J. Environ. Chem. Eng. 2021, 9, 104988-104999. [CrossRef]

54. Fang, Y.; Fu, J.; Tao, C.; Liu, P.; Cui, B. Mechanical properties and antibacterial activities of novel starch-based composite films incorporated with salicylic acid. Int. J. Biol. Macromol. 2020, 155, 1350-1358. [CrossRef] [PubMed] 
55. Chaireh, S.; Ngasatool, P.; Kaewtatip, K. Novel composite foam made from starch and water hyacinth with beeswax coating for food packaging applications. Int. J. Biol. Macromol. 2020, 165, 1382-1391. [CrossRef] [PubMed]

56. Xie, J.; Huang, L.; Wang, R.; Ye, S.; Song, X. Novel visible light-responsive graphene oxide/Bi2WO6/starch composite membrane for efficient degradation of ethylene. Carbohydr. Polym. 2020, 246, 116640-116650. [CrossRef] [PubMed]

57. Wu, K.; Yang, D.; Guo, J.; Fu, P.; Wu, R.; Zheng, Y.; Wu, M. Performance of V2O3@C composites via a sol-gel precursor assisted by soluble starch as Pt-free counter electrodes for dye sensitized solar cells. Sol. Energy 2021, 213, 126-135. [CrossRef]

58. Kizılkonca, F.B.; Torlak, E.; Erim, F. Preparation and characterization of antibacterial nano cerium oxide/chitosan/hydroxyethylcell ulose/polyethylene glycol composite films. Int. J. Biol. Macromol. 2021, 177, 351-359. [CrossRef]

59. Jain, S.K.; Dutta, A.; Kumar, J.; Shakil, N.A. Preparation and characterization of dicarboxylic acid modified starch-clay composites as carriers for pesticide delivery. Arab. J. Chem. 2020, 13, 7990-8002. [CrossRef]

60. Niu, C.; Zhang, N.; Hu, C.; Zhang, C.; Zhang, H.; Xing, Y. Preparation of a novel citric acid-crosslinked Zn-MOF/chitosan composite and application in adsorption of chromium(VI) and methyl orange from aqueous solution. Carbohydr. Polym. 2021, 258, 117644-117653. [CrossRef]

61. Zhu, J.; Zhang, X.; Qin, Z.; Zhang, L.; Ye, Y.; Cao, M.; Gao, L.; Jiao, T. Preparation of PdNPs doped chitosan-based composite hydrogels as highly efficient catalysts for reduction of 4-nitrophenol. Colloids Surf. A: Physicochem. Eng. Asp. 2021, 611, 125889-125897. [CrossRef]

62. Ibrahim, M.M.; Moustafa, H.; El Rahman, E.N.A.; Mehanny, S.; Hemida, M.H.; El-Kashif, E. Reinforcement of starch based biodegradable composite using Nile rose residues. J. Mater. Res. Technol. 2020, 9, 6160-6171. [CrossRef]

63. Begum, S.; Yuhana, N.Y.; Md Saleh, N.; Kamarudin, N.H.N.; Sulong, A.B. Review of chitosan composite as a heavy metal adsorbent: Material preparation and properties. Carbohydr. Polym. 2021, 259, 117613-117621. [CrossRef] [PubMed]

64. Nguyen, H.T.; Boonyaritthongchai, P.; Buanong, M.; Supapvanich, S.; Wongs-Aree, C. Chitosan- and k-carrageenan-based composite coating on dragon fruit (Hylocereus undatus) pretreated with plant growth regulators maintains bract chlorophyll and fruit edibility. Sci. Hortic. 2021, 281, 109916-109926. [CrossRef]

65. Coura, J.C.; Profeti, D.; Profeti, L.P.R. Eco-friendly chitosan/quartzite composite as adsorbent for dye removal. Mater. Chem. Phys. 2020, 256, 123711-123724. [CrossRef]

66. Oliveira, J.A.M.; de Santana, R.A.C.; Wanderley Neto, A.D.O. Electrophoretic deposition and characterization of chitosanmolybdenum composite coatings. Carbohydr. Polym. 2021, 255, 117382-117391. [CrossRef]

67. Ji, M.; Li, F.; Li, J.; Li, J.; Zhang, C.; Sun, K.; Guo, Z. Enhanced mechanical properties, water resistance, thermal stability, and biodegradation of the starch-sisal fibre composites with various fillers. Mater. Des. 2021, 198, 109373-109382. [CrossRef]

68. Li, P.; Gao, B.; Li, A.; Yang, H. Evaluation of the selective adsorption of silica-sand/anionized-starch composite for removal of dyes and Cupper(II) from their aqueous mixtures. Int. J. Biol. Macromol. 2020, 149, 1285-1293. [CrossRef]

69. Alharbi, A.; Shah, R.K.; Sayqal, A.; Subaihi, A.; Alluhaybi, A.A.; Algethami, F.K.; Naglah, A.M.; Almehizia, A.A.; Katouah, H.A.; Youssef, H.M. Facile synthesis of novel zinc sulfide/chitosan composite for efficient photocatalytic degradation of acid brown $5 \mathrm{G}$ and acid black 2BNG dyes. Alex. Eng. J. 2021, 60, 2167-2178. [CrossRef]

70. Novikov, I.V.; Pigaleva, M.A.; Naumkin, A.V.; Badun, G.A.; Levin, E.E.; Kharitonova, E.P.; Gromovykh, T.I.; Gallyamov, M.O. Green approach for fabrication of bacterial cellulose-chitosan composites in the solutions of carbonic acid under high pressure $\mathrm{CO}_{2}$. Carbohydr. Polym. 2021, 258, 117614-117622. [CrossRef]

71. Khan, M.A.; Chen, L.; Liang, L. Improvement in storage stability and resveratrol retention by fabrication of hollow zein-chitosan composite particles. Food Hydrocoll. 2021, 113, 106477-106490. [CrossRef]

72. Li, L.; Han, S.; Zhao, S.; Li, X.; Liu, B.; Liu, Y. Chitosan modified metal-organic frameworks as a promising carrier for oral drug delivery. RSC Adv. 2020, 10, 45130-45138. [CrossRef]

73. Yadav, S.; Mehrotra, G.K.; Dutta, P.K. Chitosan based ZnO nanoparticles loaded gallic-acid films for active food packaging. Food Chem. 2021, 334, 127605-127613. [CrossRef] [PubMed]

74. Chia, W.; Tang, D.; Khoo, K.; Lup, A.; Chew, K. Nature's fight against plastic pollution: Algae for plastic biodegradation and bioplastics production. Environ. Sci. Ecotechnol. 2020, 4, 100065-100074. [CrossRef]

75. Ghaderi, J.; Hosseini, S.; Keyvani, N.; Gómez-Guillén, M.C. Polymer blending effects on the physicochemicla and structural features of the chitosan/poly(vynil alcohol)/fish gelatin ternary biodegradable films. Food Hydrocoll. 2019, 95, 122-132. [CrossRef]

76. Cazón, P.; Vázquez, M. Applications of Chitosan as Food Packaging Materials; Crini, G., Lichtfouse, E., Eds.; Springer: Cham, Switzerland, 2019; ISBN 9783030165819.

77. Garavand, F.; Cacciotti, I.; Vahedikia, N.; Salara, A.R.; Tarhan, Ö.; Akbari-Alavijeh, S.; Shaddel, R.; Rashidinejad, A.; Nejatian, M.; Jafarzadeh, S.; et al. A comprehensive review on the nanocomposites loaded with chitosan nanoparticles for food packaging. Crit. Rev. Food Sci. Nutr. 2020, 1-34. [CrossRef] [PubMed]

78. Lekjing, S. A chitosan-based coating with or without clove oil extends the shelf life of cooked pork sausages in refrigerated storage. Meat Sci. 2016, 111, 192-197. [CrossRef] [PubMed]

79. Dehghani, S.; Hosseini, S.V.; Regenstein, J.M. Edible films and coatings in seafood preservation: A review. Food Chem. 2018, 240, 505-513. [CrossRef] [PubMed]

80. Yang, J.; Lu, H.; Li, M.; Liu, J.; Zhang, S.; Xiong, L.; Sun, Q. Development of chitosan-sodium phytate nanoparticles as a potent antibacterial agent. Carbohydr. Polym. 2017, 178, 311-321. [CrossRef] 
81. Souza, V.G.L.; Pires, J.R.A.; Rodrigues, C.; Coelhoso, I.M.; Fernando, A.L. Chitosan composites in packaging industry-current trends and future challenges. Polymers 2020, 12, 417. [CrossRef]

82. Cheba, B. Chitosan: Properties, Modifications and Food Nanobiotechnology Chitosan: Properties, Modifications and Food Nanobiotechnology. Procedia Manuf. 2020, 46, 652-658. [CrossRef]

83. Guimaráes, V.; Romani, V.; Martins, P.; da Silva, G. Innovative packaging that saves food. In Saving Food Production, Supply Chain, Food Waste and Food Consumption; Charis, M.G., Ed.; Academic Press: Cambridge, MA, USA, 2019; pp. 171-202.

84. Giteru, S.G.; Ali, M.A.; Oey, I. Solvent strength and biopolymer blending effects on physicochemical properties of zein-chitosanpolyvinyl alcohol composite films. Food Hydrocoll. 2019, 87, 270-286. [CrossRef]

85. Mohamed, N.; Madian, N.G. Evaluation of the mechanical, physical and antimicrobial properties of chitosan thin films doped with greenly synthesized silver nanoparticles. Mater. Today Commun. 2020, 25, 101372-1013779. [CrossRef]

86. Almeida, L.B.S.; Figueiredo, E.A.T.; Dias, F.G.B.; Santos, F.M.S.; Fernandes, B.D.; Vicente, A.A.; Cerqueira, M.A.; Silva, A.L.C.; Vale, D.A.; Souza, B.W.S. Antimicrobial properties of chitosan and galactomannan composite coatings and physical properties of films made thereof. Future Foods 2021, 3, 100028-100035. [CrossRef]

87. Yadav, S.; Mehrotra, G.K.; Bhartiya, P.; Singh, A.; Dutta, P.K. Preparation, physicochemical and biological evaluation of quercetin based chitosan-gelatin film for food packaging. Carbohydr. Polym. 2020, 227, 115348-115356. [CrossRef] [PubMed]

88. Zheng, K.; Xiao, S.; Lia, W.; Wang, W.; Chen, H.; Yang, F.; Qin, C. Chitosan-acorn starch-eugenol edible film: Physico-chemical, barrier, antimicrobial, antioxidant and structural properties. Int. J. Biol. Macromol. 2019, 135, 344-352. [CrossRef] [PubMed]

89. Sangroniz, A.; Zhu, J.B.; Tang, X.; Etxeberria, A.; Chen, E.Y.X.; Sardon, H. Packaging materials with desired mechanical and barrier properties and full chemical recyclability. Nat. Commun. 2019, 10, 1-7. [CrossRef]

90. Wang, H.; Ding, F.; Ma, L.; Zhang, Y. Edible films from chitosan-gelatin: Physical properties and food packaging application. Food Biosci. 2021, 40, 100871-100888. [CrossRef]

91. García, M.A.; Rodríguez, M.; Castro, C.; de la Paz, N. Water Vapor Permeability of Chitosan/Zeolite Composite Films as Affected by Biopolymer and Zeolite Microparticle Concentrations. J. Packag. Technol. Res. 2020, 4, 157-169. [CrossRef]

92. Lin, D.; Zheng, Y.; Huang, Y.; Ni, L.; Zhao, J.; Huang, C.; Chen, X.; Chen, X.; Wu, Z.; Wu, D.; et al. Investigation of the structural, physical properties, antioxidant, and antimicrobial activity of chitosan- nano-silicon aerogel composite edible films incorporated with okara powder. Carbohydr. Polym. 2020, 250, 116842-116850. [CrossRef] [PubMed]

93. Cazón, P.; Velázquez, G.; Vázquez, M. Characterization of bacterial cellulose films combined with chitosan and polyvinyl alcohol: Evaluation of mechanical and barrier properties. Carbohydr. Polym. 2019, 216, 72-85. [CrossRef]

94. Han, L.F.; Tan, C.P.; Zawawi, R.M.; Nur, N.H. Effect of sonication time and heat treatment on the structural and physical properties of chitosan/graphene oxide nanocomposite films. Food Packag. Shelf Life 2021, 28, 100663-100673.

95. Zhang, X.; Li, Y.; Guo, M.; Jin, T.; Ali Arabie, S.; He, Q.; Ismail, B.; Hu, Y.; Liu, D. Antimicrobial and UV Blocking Properties of Composite Chitosan Films with Curcumin Grafted Cellulose Nanofiber. Food Hydrocoll. 2021, 112, 106337-106347. [CrossRef]

96. Narasagoudr, S.S.; Hegde, V.G.; Chougale, R.B.; Masti, S.P.; Dixit, S. Influence of boswellic acid on multifunctional properties of chitosan/poly (vinyl alcohol) films for active food packaging. Int. J. Biol. Macromol. 2020, 154, 48-61. [CrossRef] [PubMed]

97. Merz, B.; Capello, C.; Leandro, G.C.; Moritz, D.E.; Monteiro, A.R.; Valencia, G.A. A novel colorimetric indicator film based on chitosan, polyvinyl alcohol and anthocyanins from jambolan (Syzygium cumini) fruit for monitoring shrimp freshness. Int. J. Biol. Macromol. 2020, 153, 625-632. [CrossRef] [PubMed]

98. Sani Karimi, I.; Pirsa, S.; Tağı, Ş. Preparation of chitosan/zinc oxide/Melissa officinalis essential oil nano-composite film and evaluation of physical, mechanical and antimicrobial properties by response surface method. Polym. Test. 2019, 79, 106004-106013. [CrossRef]

99. Deshmukh, A.R.; Aloui, H.; Khomlaem, C.; Negi, A.; Yun, J.H.; Kim, H.S.; Kim, B.S. Biodegradable films based on chitosan and defatted Chlorella biomass: Functional and physical characterization. Food Chem. 2021, 337, 127777-127786. [CrossRef]

100. Xu, T.; Gao, C.; Feng, X.; Huang, M.; Yang, Y.; Shen, X.; Tang, X. Cinnamon and clove essential oils to improve physical, thermal and antimicrobial properties of chitosan-gum arabic polyelectrolyte complexed films. Carbohydr. Polym. 2019, 217, 116-125. [CrossRef]

101. Ahmad, N.; Wee, C.E.; Wai, L.K.; Zin, N.M.; Azmi, F. Biomimetic amphiphilic chitosan nanoparticles: Synthesis, characterization and antimicrobial activity. Carbohydr. Polym. 2021, 254, 117299-117306. [CrossRef] [PubMed]

102. Abd El-Hack, M.E.; El-Saadony, M.T.; Shafi, M.E.; Zabermawi, N.M.; Arif, M.; Batiha, G.E.; Khafaga, A.F.; Abd El-Hakim, Y.M.; Al-Sagheer, A.A. Antimicrobial and antioxidant properties of chitosan and its derivatives and their applications: A review. Int. J. Biol. Macromol. 2020, 164, 2726-2744. [CrossRef]

103. Kumar, S.; Mukherjee, A.; Dutta, J. Chitosan based nanocomposite films and coatings: Emerging antimicrobial food packaging alternatives. Trends Food Sci. Technol. 2020, 97, 196-209. [CrossRef]

104. Kong, M.; Chen, X.G.; Xing, K.; Park, H.J. Antimicrobial properties of chitosan and mode of action: A state of the art review. Int. J. Food Microbiol. 2010, 144, 51-63. [CrossRef]

105. Râpă, M.; Miteluţ, A.C.; Tănase, E.E.; Grosu, E.; Popescu, P.; Popa, M.E.; Rosnes, J.T.; Sivertsvik, M.; Darie-Niţă, R.N.; Vasile, C. Influence of chitosan on mechanical, thermal, barrier and antimicrobial properties of PLA-biocomposites for food packaging. Compos. Part B Eng. 2016, 102, 112-121. [CrossRef] 
106. Moeini, A.; Mallardo, S.; Cimmino, A.; Dal Poggetto, G.; Masi, M.; Di Biase, M.; van Reenen, A.; Lavermicocca, P.; Valerio, F.; Evidente, A.; et al. Thermoplastic starch and bioactive chitosan sub-microparticle biocomposites: Antifungal and chemicophysical properties of the films. Carbohydr. Polym. 2020, 230, 115627-115635. [CrossRef] [PubMed]

107. Virgili, A.H.; Laranja, D.C.; Malheiros, P.S.; Pereira, M.B.; Costa, T.M.H.; de Menezes, E.W. Nanocomposite film with antimicrobial activity based on gold nanoparticles, chitosan and aminopropylsilane. Surf. Coat. Technol. 2021, 415, 127086-127092. [CrossRef]

108. Yao, X.; Hu, H.; Qin, Y.; Liu, J. Development of antioxidant, antimicrobial and ammonia-sensitive films based on quaternary ammonium chitosan, polyvinyl alcohol and betalains-rich cactus pears (Opuntia ficus-indica) extract. Food Hydrocoll. 2020, 106, 105896-105904. [CrossRef]

109. Fang, Y.; Xing, C.; Liu, J.; Zhang, Y.; Li, M.; Han, Q. Supermolecular film crosslinked by polyoxometalate and chitosan with superior antimicrobial effect. Int. J. Biol. Macromol. 2020, 154, 732-738. [CrossRef]

110. Souza, V.G.L.; Pires, J.R.A.; Rodrigues, C.; Rodrigues, P.F.; Lopes, A.; Silva, R.J.; Caldeira, J.; Duarte, M.P.; Fernandes, F.B.; Coelhoso, I.M.; et al. Physical and morphological characterization of chitosan/montmorillonite films incorporated with ginger essential oil. Coatings 2019, 9, 700. [CrossRef]

111. Hasan, M.; Rusman, R.; Khaldun, I.; Ardana, L.; Mudatsir, M.; Fansuri, H. Active edible sugar palm starch-chitosan films carrying extra virgin olive oil: Barrier, thermo-mechanical, antioxidant, and antimicrobial properties. Int. J. Biol. Macromol. 2020, 163, 766-775. [CrossRef]

112. Aguirre-Loredo, R.Y.; Rodríguez-Hernández, A.I.; Morales-Sánchez, E.; Gómez-Aldapa, C.A.; Velazquez, G. Effect of equilibrium moisture content on barrier, mechanical and thermal properties of chitosan films. Food Chem. 2016, 196, 560-566. [CrossRef]

113. Zhang, R.; Wang, X.; Cheng, M. Preparation and characterization of potato starch film with various size of $\mathrm{Nano}^{-S i O}$. Polymers 2018, 10, 1172. [CrossRef]

114. Koc, B.; Lalehan, A.; Cakmak Selim, Y.; Sargin, I.; Salaberria, A.M.; Labidi, J.; Ilk, S.; Cekic Ozlem, F.; Akata, I.; Kaya, M. Production and characterization of chitosan-fungal extract films. Food Biosci. 2020, 35, 100545-100553. [CrossRef]

115. Costa, S.M.; Ferreira, D.P.; Teixeira, P.; Ballesteros, L.F.; Teixeira, J.A.; Fangueiro, R. Active natural-based films for food packaging applications: The combined effect of chitosan and nanocellulose. Int. J. Biol. Macromol. 2021, 177, 241-251. [CrossRef] [PubMed]

116. Gaspar, M.C.; Leocádio, J.; Mendes, C.V.T.; Cardeira, M.; Fernández, N.; Matias, A.; Carvalho, M.G.V.S.; Braga, M.E.M. Biodegradable film production from agroforestry and fishery residues with active compounds. Food Packag. Shelf Life 2021, 28, 100661-100674. [CrossRef]

117. Kalita, N.K.; Nagar, M.K.; Mudenur, C.; Kalamdhad, A.; Katiyar, V. Biodegradation of modified Poly(lactic acid) based biocomposite films under thermophilic composting conditions. Polym. Test. 2019, 76, 522-536. [CrossRef]

118. Chinaglia, S.; Tosin, M.; Degli-Innocenti, F. Biodegradation rate of biodegradable plastics at molecular level. Polym. Degrad. Stab. 2018, 147, 237-244. [CrossRef]

119. Zhu, L.-Y.; Lin, D.-Q.; Yao, S.-J. Biodegradation of polyelectrolyte complex films composed of chitosan and sodium cellulose sulfate as the controllable release carrier. Carbohydr. Polym. 2010, 82, 323-328. [CrossRef]

120. Gie Gan, P.; Sung Ting, S.; Abdullah, M.F.; Omar Firdaus, M.; Tan Kian, W. Water resistance and biodegradation properties of conventionally-heated and microwave-cured cross-linked cellulose nanocrystal/chitosan composite films. Polym. Degrad. Stab. 2021, 188, 109563-109574. [CrossRef]

121. Dean, K.; Sangwan, P.; Way, C.; Zhang, X.; Martino, V.P.; Xie, F.; Halley, P.J.; Pollet, E.; Avérous, L. Glycerol plasticised chitosan: A study of biodegradation via carbon dioxide evolution and nuclear magnetic resonance. Polym. Degrad. Stab. 2013, 98, 1236-1246. [CrossRef]

122. Ahamad, T.; Naushad, M.; Mousa, R.H.; Alshehri, S.M. Fabrication of starch-salicylaldehyde based polymer nanocomposite (PNC) for the removal of pollutants from contaminated water. Int. J. Biol. Macromol. 2020, 165, 2731-2738. [CrossRef]

123. Tao, X.; Liu, D.; Cong, W.; Huang, L. Controllable synthesis of starch-modified ZnMgAl-LDHs for adsorption property improvement. Appl. Surf. Sci. 2018, 457, 572-579. [CrossRef]

124. Priyanka, M.; Saravanakumar, M.P. Ultrahigh adsorption capacity of starch derived zinc based carbon foam for adsorption of toxic dyes and its preliminary investigation on oil-water separation. J. Clean. Prod. 2018, 197, 511-524. [CrossRef]

125. Stan, M.; Lung, I.; Soran, M.L.; Leostean, C.; Popa, A.; Stefan, M.; Lazar, M.D.; Opris, O.; Silipas, T.D.; Porav, A.S. Removal of antibiotics from aqueous solutions by green synthesized magnetite nanoparticles with selected agro-waste extracts. Process Saf. Environ. Prot. 2017, 107, 357-372. [CrossRef]

126. Muzaffar, S.; Tahir, H. Enhanced synthesis of silver nanoparticles by combination of plants extract and starch for the removal of cationic dye from simulated waste water using response surface methodology. J. Mol. Liq. 2018, 252, 368-382. [CrossRef]

127. Alvarado, N.; Abarca, R.L.; Urdaneta, J.; Romero, J.; Galotto, M.J.; Guarda, A. Cassava starch: Structural modification for development of a bio-adsorber for aqueous pollutants. Characterization and adsorption studies on methylene blue. Polym. Bull. 2021, 78, 1087-1107. [CrossRef]

128. Xu, F.; Chen, H.; Dai, Y.; Wu, S.; Tang, X. Arsenic adsorption and removal by a new starch stabilized ferromanganese binary oxide in water. J. Environ. Manag. 2019, 245, 160-167. [CrossRef] [PubMed]

129. Dai, M.; Liu, Y.; Ju, B.; Tian, Y. Preparation of thermoresponsive alginate/starch ether composite hydrogel and its application to the removal of $\mathrm{Cu}$ (II) from aqueous solution. Bioresour. Technol. 2019, 294, 122192-122199. [CrossRef]

130. Yang, C.; Ge, C.; Li, X.; Li, L.; Wang, B.; Lin, A.; Yang, W. Does soluble starch improve the removal of Cr(VI) by nZVI loaded on biochar? Ecotoxicol. Environ. Saf. 2021, 208, 111552-111560. [CrossRef] 
131. Mittal, H.; Alhassan, S.M.; Ray, S.S. Efficient organic dye removal from wastewater by magnetic carbonaceous adsorbent prepared from corn starch. J. Environ. Chem. Eng. 2018, 6, 7119-7131. [CrossRef]

132. Naushad, M.; Ahamad, T.; Sharma, G.; Al-Muhtaseb, A.H.; Albadarin, A.B.; Alam, M.M.; ALOthman, Z.A.; Alshehri, S.M.; Ghfar, A.A. Synthesis and characterization of a new starch $/ \mathrm{SnO}_{2}$ nanocomposite for efficient adsorption of toxic $\mathrm{Hg}^{2+}$ metal ion. Chem. Eng. J. 2016, 300, 306-316. [CrossRef]

133. Fu, Y.; Yang, C.; Zheng, Y.; Jiang, J.; Sun, Y.; Chen, F.; Hu, J. Sulfur crosslinked poly(m-aminothiophenol)/potato starch on mesoporous silica for efficient $\mathrm{Hg}$ (II) removal and reutilization of waste adsorbent as a catalyst. J. Mol. Liq. 2021, 328, 115420-115431. [CrossRef]

134. Liu, F.; Peng, G.; Li, T.; Yu, G.; Deng, S. Au(III) adsorption and reduction to gold particles on cost-effective tannin acid immobilized dialdehyde corn starch. Chem. Eng. J. 2019, 370, 228-236. [CrossRef]

135. Xue, Y.; Chang, Q.; Hu, X.; Cai, J.; Yang, H. A simple strategy for selective photocatalysis degradation of organic dyes through selective adsorption enrichment by using a complex film of CdS and carboxylmethyl starch. J. Environ. Manag. 2020, 274, 111184-111194. [CrossRef]

136. Stan, M.; Lung, I.; Soran, M.L.; Opris, O.; Leostean, C.; Popa, A.; Copaciu, F.; Lazar, M.D.; Kacso, I.; Silipas, T.D.; et al. Starchcoated green synthesized magnetite nanoparticles for removal of textile dye Optilan Blue from aqueous media. J. Taiwan Inst. Chem. Eng. 2019, 100, 65-73. [CrossRef]

137. Perez, T.; Pasquini, D.; De Faria Lima, A.; Rosa, E.V.; Sousa, M.H.; Cerqueira, D.A.; De Morais, L.C. Efficient removal of lead ions from water by magnetic nanosorbents based on manganese ferrite nanoparticles capped with thin layers of modified biopolymers. J. Environ. Chem. Eng. 2019, 7, 102892-1028104. [CrossRef]

138. Okuo, J.; Emina, A.; Omorogbe, S.; Anegbe, B. Synthesis, characterization and application of starch stabilized zerovalent iron nanoparticles in the remediation of Pb-acid battery soil. Environ. Nanotechnol. Monit. Manag. 2018, 9, 12-17. [CrossRef]

139. Gong, Y.; Wang, L.; Liu, J.; Tang, J.; Zhao, D. Science of the Total Environment Removal of aqueous per fl uorooctanoic acid (PFOA) using starch-stabilized magnetite nanoparticles. Sci. Total Environ. 2016, 562, 191-200. [CrossRef]

140. Mofradnia, S.R.; Ashouri, R.; Tavakoli, Z.; Shahmoradi, F.; Rashedi, H.; Yazdian, F. Effect of zero-valent iron/starch nanoparticle on nitrate removal using MD simulation. Int. J. Biol. Macromol. 2019, 121, 727-733. [CrossRef]

141. Cui, F.; Zi, H.; Liu, H.; Zhang, S.; Yuan, B. A study of starch-urea-water mixtures with a combination of molecular dynamics simulation and traditional characterization methods. Int. J. Biol. Macromol. 2020, 148, 121-128. [CrossRef]

142. Bhopatkar, D.; Feng, T.; Chen, F.; Zhang, G.; Carignano, M.; Park, S.H.; Zhuang, H.; Campanella, O.H.; Hamaker, B.R. Selfassembled nanoparticle of common food constituents that carries a sparingly soluble small molecule. J. Agric. Food Chem. 2015, 63, 4312-4319. [CrossRef]

143. Dodda, L.S.; Vilseck, J.Z.; Tirado-Rives, J.; Jorgensen, W.L. 1.14*CM1A-LBCC: Localized Bond-Charge Corrected CM1A Charges for Condensed-Phase Simulations. J. Phys. Chem. B 2017, 121, 3864-3870. [CrossRef]

144. Dodda, L.S.; De Vaca, I.C.; Tirado-Rives, J.; Jorgensen, W.L. LigParGen web server: An automatic OPLS-AA parameter generator for organic ligands. Nucleic Acids Res. 2017, 45, W331-W336. [CrossRef]

145. Jorgensen, W.L.; Tirado-Rives, J. Potential energy functions for atomic-level simulations of water and organic and biomolecular systems. Proc. Natl. Acad. Sci. USA 2005, 102, 6665-6670. [CrossRef] [PubMed]

146. Parrinello, M.; Rahman, A. Polymorphic transitions in single crystals: A new molecular dynamics method. J. Appl. Phys. 1981, 52, 7182-7190. [CrossRef]

147. Bashir, A.; Manzoor, T.; Malik, L.A.; Qureashi, A.; Pandith, A.H. Enhanced and Selective Adsorption of Zn(II), Pb(II), Cd(II), and $\mathrm{Hg}$ (II) Ions by a Dumbbell- And Flower-Shaped Potato Starch Phosphate Polymer: A Combined Experimental and DFT Calculation Study. ACS Omega 2020, 5, 4853-4867. [CrossRef] [PubMed]

148. Zarei, S.; Niad, M.; Raanaei, H. The removal of mercury ion pollution by using Fe3O4-nanocellulose: Synthesis, characterizations and DFT studies. J. Hazard. Mater. 2018, 344, 258-273. [CrossRef]

149. Li, X.; Wang, S.; Liu, Y.; Jiang, L.; Song, B.; Li, M.; Zeng, G.; Tan, X.; Cai, X.; Ding, Y. Adsorption of Cu(II), Pb(II), and Cd(II) ions from acidic aqueous solutions by diethylenetriaminepentaacetic acid-modified magnetic graphene oxide. J. Chem. Eng. Data 2017, 62, 407-416. [CrossRef]

150. Becke, A.D. Density-functional thermochemistry. III. The role of exact exchange. J. Chem. Phys. 1993, 98, 5648-5652. [CrossRef]

151. Wang, L.; Xu, W.H.; Yang, R.; Zhou, T.; Hou, D.; Zheng, X.; Liu, J.H.; Huang, X.J. Electrochemical and density functional theory investigation on high selectivity and sensitivity of exfoliated nano-zirconium phosphate toward lead(II). Anal. Chem. 2013, 85, 3984-3990. [CrossRef]

152. Suo, F.; Liu, X.; Li, C.; Yuan, M.; Zhang, B.; Wang, J.; Ma, Y.; Lai, Z.; Ji, M. Mesoporous activated carbon from starch for superior rapid pesticides removal. Int. J. Biol. Macromol. 2019, 121, 806-813. [CrossRef] 